\title{
Access Surgeries and Osteotomies for the Maxillofacial Region
}

\author{
Madan G. Ethunandan
}

\subsection{Bicoronal Scalp Flap}

The bicoronal flap was first described by Hartley and Kenyon [1] to access the cranium and popularised by Tessier [2] to provide additional access to the orbits and midface. Various modifications of the flap have been described and include a zigzag (stealth) incision [3], deeper plane of dissection in the temporal scalp region to avoid damage to the facial nerve [4, 5] and strategies to minimise alopecia [6].

The coronal flap provides access to the skull, anterior and middle cranial fossa, upper midface including the nasoethmoid region and orbits and temporal and infratemporal fossa.

The SCALP is an acronym consists of five layers: Skin, subCutaneous connective tissue, galea Aponeurotica, Loose areolar tissue and Pericranium. The first three layers are firmly attached to each other and are raised as a single layer, superficial to the loose areolar tissue (avascular plane of Merkel). The blood vessels and nerves run within the first three layers. The "perceived" complexity of the layers in the temporal region can be rationalised, if one was to consider the galea aponeurotica as a single layer which extends to the temporal region as the "temporoparietal fascia" (synonymsuperficial temporal fascia/supra-zygomatic SMAS) and the pericranium extending as the "temporalis fascia" (synonymdeep temporal fascia) overlying the temporalis muscle. The deep temporal fascia divides about $2-3 \mathrm{~cm}$ superior to the zygomatic arch into a superficial and deep layers. The temporoparietal fascia, superficial layer of the deep temporal fascia and the periosteum of the zygomatic arch fuse together on the lateral aspect of the zygomatic arch and contain the frontal branch of the facial nerve. The superficial temporal fat pad is present between the superficial and deep layer of the deep temporal fascia, with the deep layer attached to the deep

M. G. Ethunandan $(\bowtie)$

Consultant Oral and Maxillofacial/Skull Base Surgeon,

Honorary Senior Clinical Lecturer, Lead, Head and Neck Cancer,

University Hospital Southampton, Southampton, UK aspect of the zygomatic arch. Dissection deep to the galea and the temporoparietal fascia affords a relatively bloodless plane and maintains and preserves the blood supply and avoids damage to the nerves, including the frontal branch of the facial nerve. This "safe" plane of dissection can be between the temporalis muscle and the "undivided" deep temporal fascia or (more inferiorly) between the superficial and deep layers of the "divided" deep temporal fascia (Fig. 85.1a).

The frontal branch of the facial nerve crosses the zygomatic arch at least $8 \mathrm{~mm}$ (range $8-32 \mathrm{~mm}$ ) in front of the external auditory meatus, at least $1 \mathrm{~cm}$ anterior to the superior attachment of the helix to the scalp, and runs no further than $2 \mathrm{~cm}$ above the frontozygomatic suture (Fig. 85.1b).

\subsubsection{Procedure}

The hair along the incision line can be parted or a small strip shaved. Local anaesthetic containing 1: 200,000 adrenaline is infiltrated above the galea for appropriate haemostasis (you know you are in the right plane if increased resistance is felt. If it is easy to inject, you are in the deeper loose areolar tissue plane). The incision is marked from the anterior attachment of the helix and carried over the vault to the opposite side, inside the hairline (Fig. 85.1c). It can stop at the midline, if only unilateral access is required. If repeated access is likely to be required to the cranial skeleton, it would be useful to incorporate a posteriorly directed "curve", just above the helical attachment to the scalp, to try and avoid injury to the anterior branch of the superficial temporal artery and maintain additional vascularity to the flap. A "bevelled" incision can be made parallel to the hair follicles to minimise alopecia, and a "zigzag" can be incorporated to reduce parting of the hair along a straight incision line. When designing the flap in male patients, the likely influence of male pattern baldness should be taken into account.

The incision commences at the vertex between the superior temporal lines and is made with a blade through the 

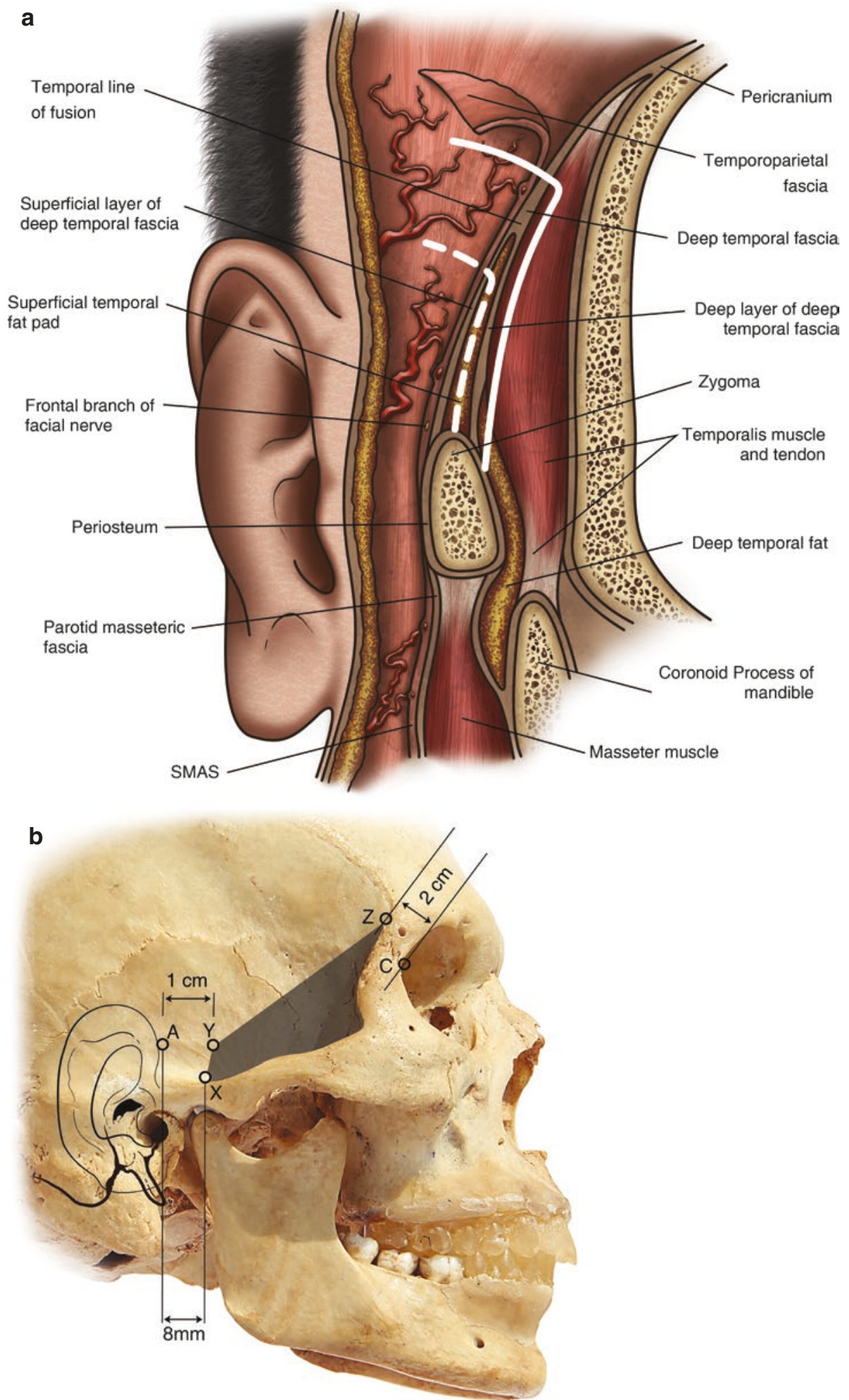

(O)Association of Oral and Maxillofacial Surgeons of India

Fig. 85.1 Scalp flap. (a) Layers of the scalp in the temporal region. Dotted line-dissection between the superficial and deep layers of the (divided) deep temporal fascia. Solid line-dissection between the (undivided) deep temporal fascia and temporalis muscle. (b) Position of the frontal branch of the facial nerve. (c) Skin marking for a coronal flap. (d) Pericranial flap raised as an extension of the deep temporal fascia incision (note same plane of dissection). (e) Incision marked on the undivided deep temporal fascia. (f) Periosteal tunnel created along the zygomatic arch, deep to the position of the frontal branch of the facial nerve. (g) Exposure of the lateral orbit and zygomatic arch. (h) Temporalis muscle retracted to expose the temporal fossa and lateral orbital wall 

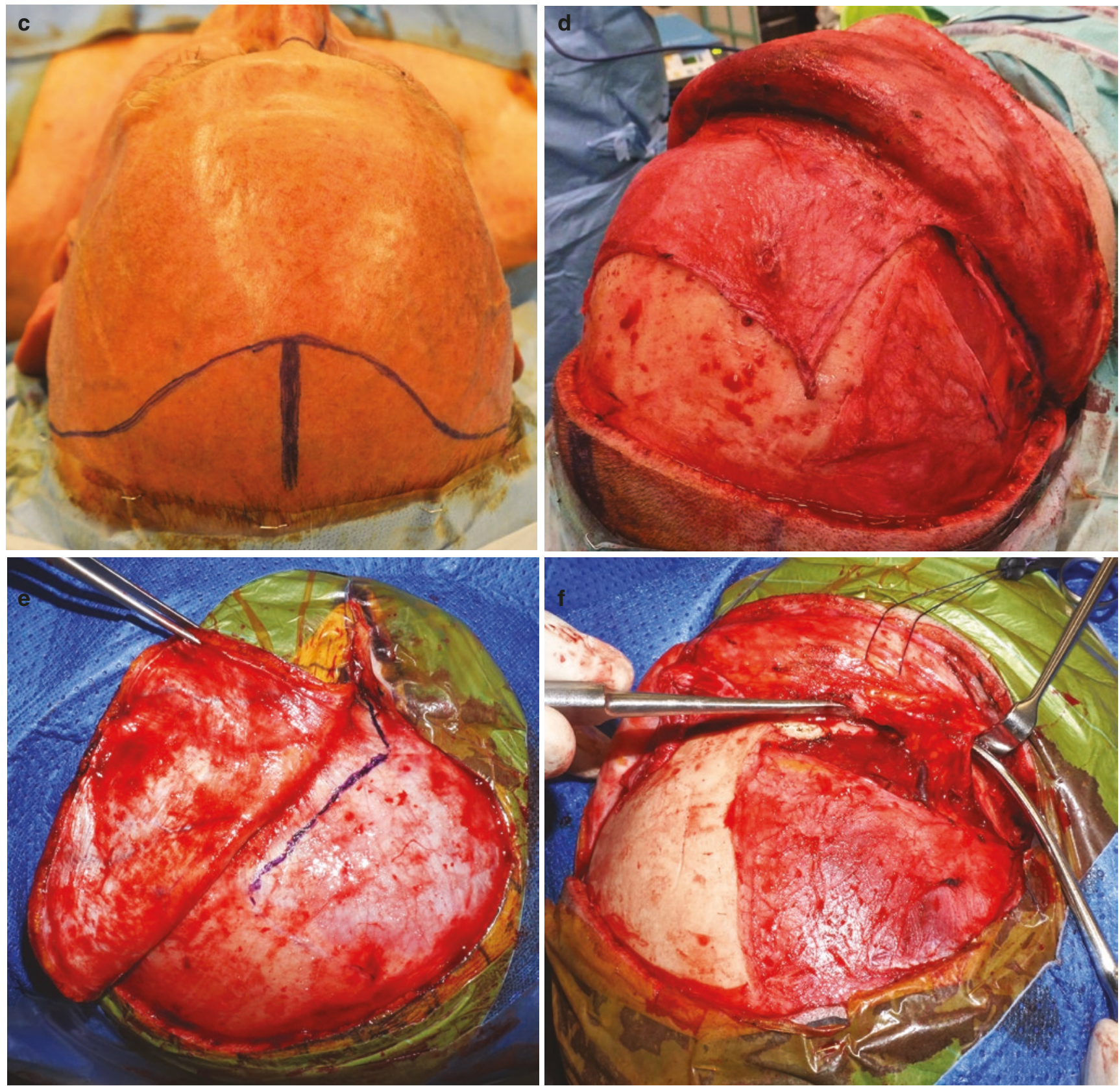

CAssociation of Oral and Maxillofacial Surgeons of India

Fig. 85.1 (continued) 


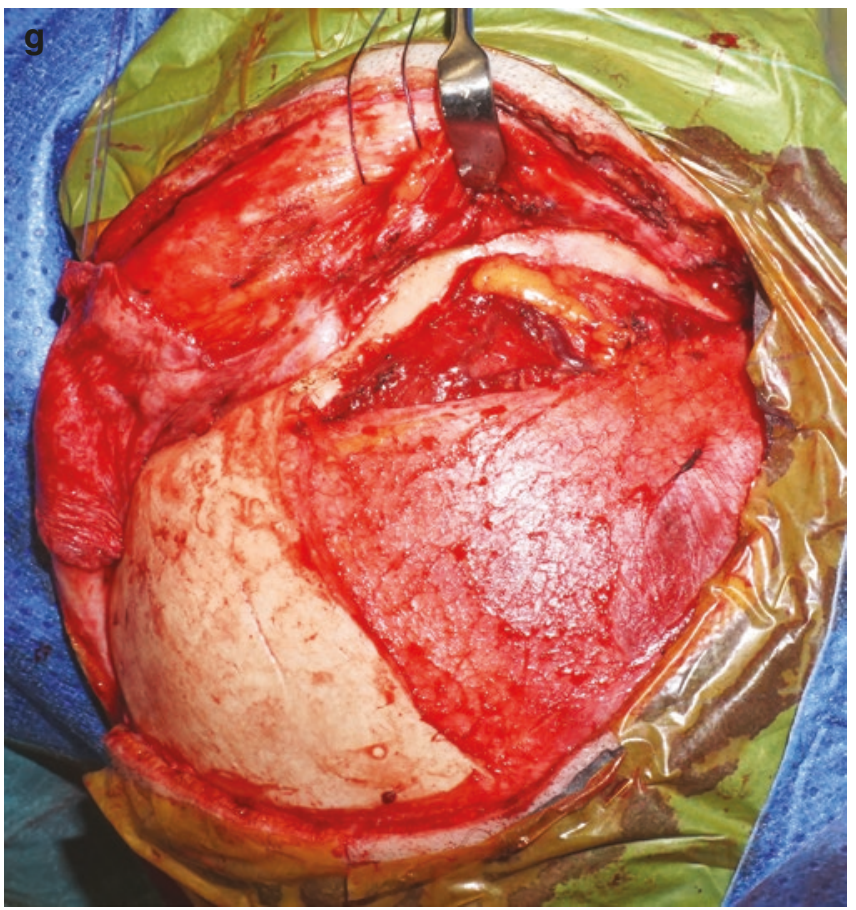

CAssociation of Oral and Maxillofacial Surgeons of India

Fig. 85.1 (continued)

galea, up to the loose areolar tissue, and the superficial three layers are raised as a unit. Blunt scissors or a brain retractor can be used to undermine the incision line along this plane, down to the root of the helix, and with the brain retractor in situ, the incision is made down to it. This allows rapid elevation of the flap, without inadvertent damage to the underling temporal fascia/temporalis muscle. Dissection is carried inferiorly in the subgaleal plane. The pericranium is incised approximately $3 \mathrm{~cm}$ above the superior orbital rim, and the dissection continued subperiosteally. Resistance can be encountered in the frontozygomatic and frontonasal suture region and around the supraorbital neurovascular bundles. If the supraorbital neurovascular bundle is present within a foramen, rather than a notch, the foramen can be opened with careful use of a fine osteotome (divergent cuts to minimise damage and ease of release).

A pericranial flap could be easily incorporated, by extending the pericranial incision superiorly to the required length, between the superior temporal lines, as an extension of the temporalis fascia incision (Fig. 85.1d). If a pericranial flap is to be utilised, the subgaleal dissection should stop $2 \mathrm{~cm}$ above the supraorbital rim, to maintain the vascularity of the pericranial flap.

Exposure of the nasal bones and frontal process of the maxilla can be facilitated by a vertical periosteal releasing incision in the midline. The medial canthal ligaments can be detached from the anterior lacrimal crest, which provides excellent exposure of the medial orbit up to the optic canal and the medial floor up to the infraorbital nerve.

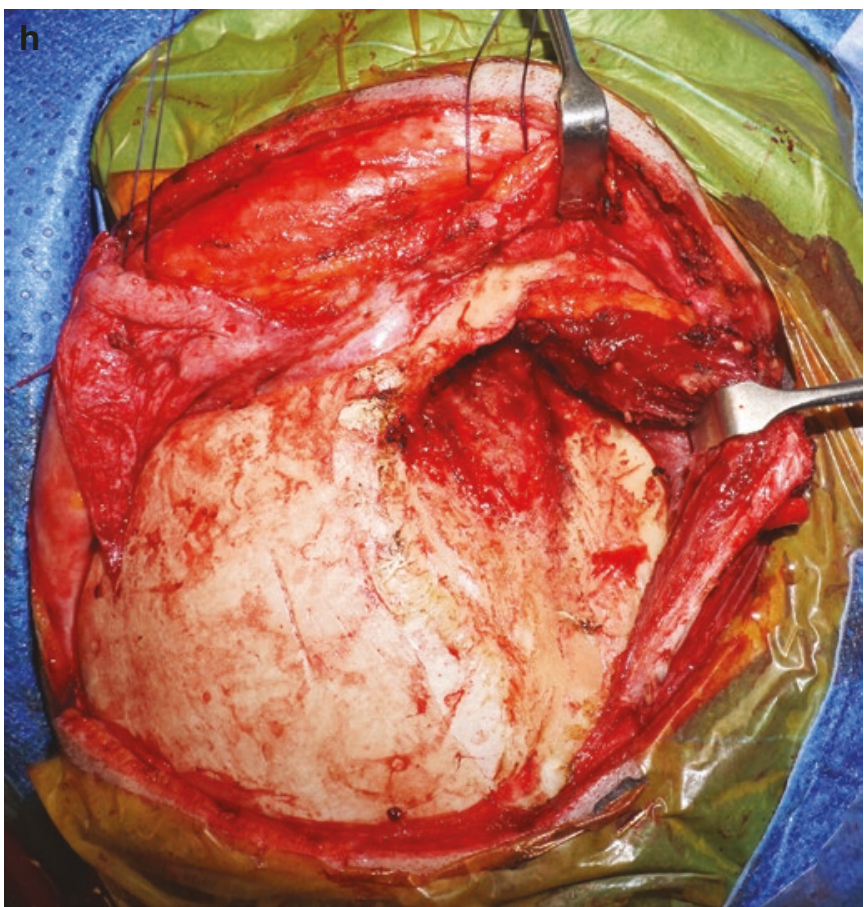

The detached medial canthal tendon must be "tagged" through the periosteum with a unresorbable suture on a round-bodied needle, for subsequent reattachment to a microplate. Subperiosteal dissection medially is now possible as far as the floor of the orbit.

The skin incision is extended inferiorly in a naturally occurring skin crease, to just below the cartilaginous meatus, if exposure of the zygoma, lateral orbit or temporomandibular joint is considered. This could be modified to follow the free edge of the tragus, to make this section less conspicuous. The dissection is carried forward medially following the cartilaginous meatus. At the superior attachment of the helix, the temporalis fascia is incised $-1 \mathrm{~cm}$ above the zygomatic arch, and angled forwards to join the supraorbital periosteal incision $3 \mathrm{~cm}$ above the supraorbital rim (Fig. 85.1e). The incision is extended vertically in along the temporal fascia to the root of the zygomatic arch, which can be felt on palpation above the cartilaginous meatus. A pocket is created at the root of the zygomatic arch, deep to the periosteum and the soft tissues tented with a periosteal elevator to expose the arch. The soft tissues superior to the arch, on the surface of the temporalis muscle, can be transected down to the periosteal elevator to expose the zygomatic arch, zygoma and lateral orbit, without damaging the frontal branch (Fig. 85.1f, g).

Retraction of the temporalis muscle posteriorly provides additional exposure to the temporal fossa and the superior boundary of the infratemporal fossa (Fig. 85.1h). 
Closure of the galea and meticulous haemostasis is essential, and drains and/or head dressing can be additionally utilised to prevent haematomas.

\subsubsection{Potential Complications and Solutions (Clinical Pearls)}

Alopecia: Use a knife for skin incision, meticulous haemostasis with judicious use of bipolar diathermy and tensionfree closure.

Frontal nerve damage: Appropriate plane of dissection, care during retraction and the use of diathermy in the temporal/ preauricular region.

Supraorbital/supra-trochlear nerve damage: Care during dissection in the supraorbital rim region and judicious use of fine/sharp osteotomes when deroofing the supraorbital foramen

\section{Clinical Tips}

- Inject vasoconstrictor above the galea, make the incision in segments with a blade and use bipolar diathermy to achieve meticulous haemostasis and reduce blood loss.

- Consider making the incision parallel to the hair follicles and use bipolar diathermy "judiciously" to minimise alopecia.

- Start the incision in between the superior temporal lines to "easily" identify the appropriate plane of dissection.

- Stay deep to the galea in the temporal region to avoid injury to the frontal branch of the facial nerve.

- An easier and safer plane of dissection would be between the temporalis muscle and the deep temporal fascia.

- Stop dissection in the subgaleal plane, $2 \mathrm{~cm}$ above the supraorbital rims, if a pericranial flap is planned, to preserve its vascularity.

- Place deep sutures along the galea for "tensionfree" skin closure but away from the skin surface to minimise "stitch" abscesses.

\subsection{Midface Access}

A modified Weber-Fergusson approach remains the most popular transfacial approach to the midface. This access was originally described well over 150 years ago by Weber [7] from Germany and Fergusson [8] from the United Kingdom.
Various modifications have been incorporated over the years, and the more commonly used ones include the midline lip incision being placed on the philtrum [9], lateral eyelid extension [10] and medial eyebrow extension [11]. The original lateral rhinotomy incision was described by Moure [12], and a modification of the nasal component to lie along the nasal subunits was described by Thankappan [13].

A modified Weber-Fergusson incision provides excellent access to the ipsilateral maxilla and, with appropriate extensions, provides additional exposure to the nasal cavity, orbit and ethmoid (Fig. 85.2a). The "nasal" part of the incision can be utilised for a lateral rhinotomy access.

A Le Fort I down-fracture osteotomy can also be utilised to access the nasal cavity, maxillary antrum, pterygopalatine fossa and clivus. However, with the widespread use of endonasal endoscopic techniques, its use has become limited. The technique is similar to that utilised in orthognathic surgery and is outlined in the orthognathic surgery chapter.

An intraoral vestibular incision can be joined with bilateral piriform fossa and intercartilaginous and septocolumellar transfixion incisions to "deglove" the upper lip, cheek and soft tissues of the nose to provide access to the maxilla and nasal cavity $[14,15]$.

A maxillary swing procedure can be utilised to access the posterior maxilla, pterygopalatine/infratemporal fossa and nasopharynx. However, with the widespread use of endoscopic techniques, its role has also become limited. Its principal use is in the management of recurrent nasopharyngeal tumours, which cannot be accessed endoscopically [16].

The modified Weber-Fergusson commences with an upper lip split incision that is made along the philtrum and extended along the alar margins. A "V" can be incorporated along the nasal floor to improve localisation of the flap during closure. The incision is carried along the alar margin and extended superiorly at the junction between the nasal side wall and dorsal nasal subunit (Fig. 85.2a).

The intraoral incisions are made along the gingival crevice or buccal vestibule and are principally determined by the location of the tumour. A "V" can be incorporated in the lip mucosa to facilitate accurate approximation during wound closure. The cheek flap is elevated to expose the maxilla (Fig. 85.2b). The plane of dissection is principally determined by the extension of the tumour. A "tonsil" swab can be placed in the nasal cavity and soft tissues along the piriform rim transected to gain access to the nasal cavity and avoid inadvertent damage to the nasal septum.

Lateral extensions can be incorporated, if additional access is required to the orbits and zygoma. This is made along the subciliary/midtarsal skin crease and can be extended laterally along the crow's feet skin crease (Fig. 85.2a). Care is taken to elevate the skin flap "superfi- 

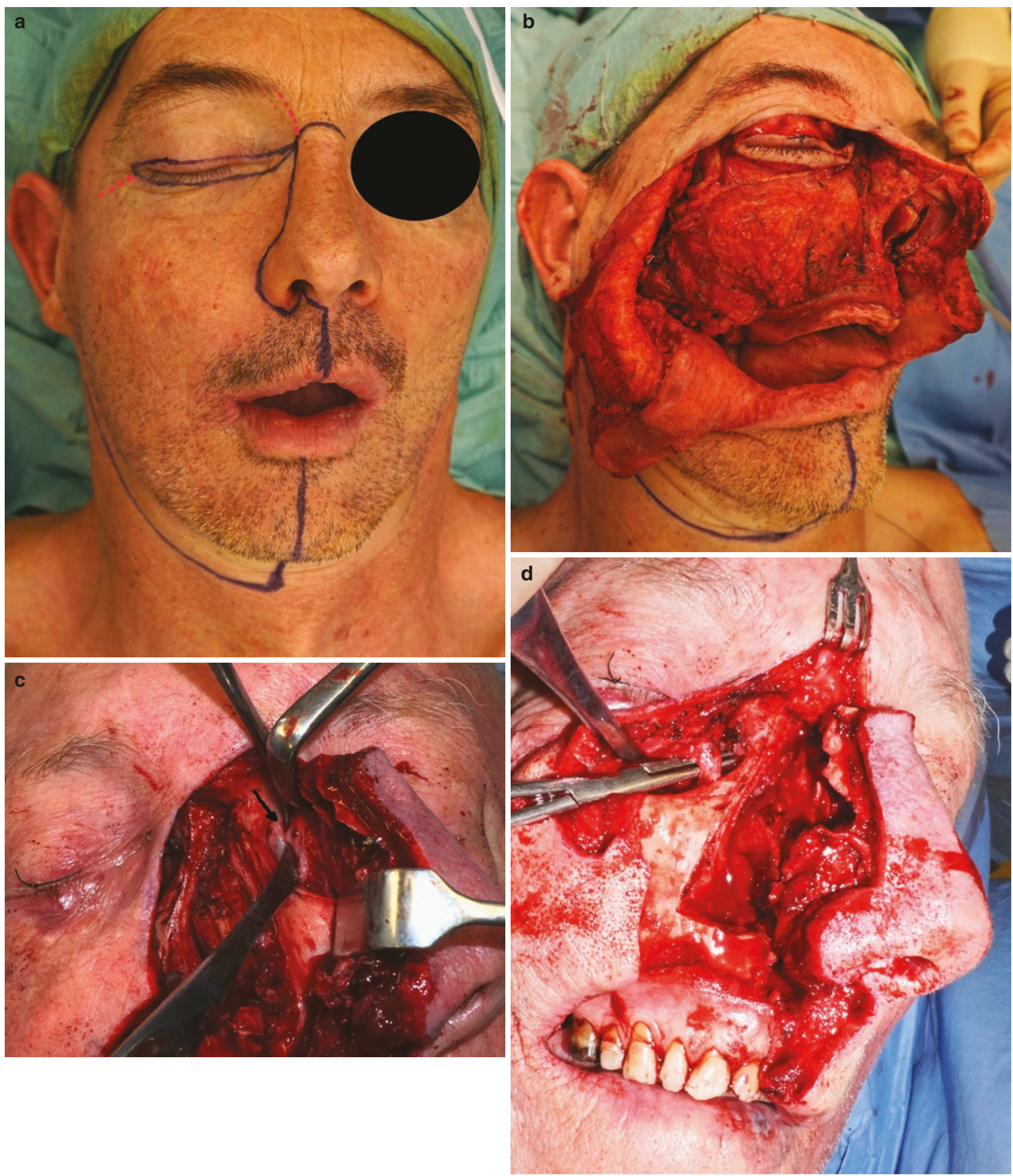

(C)Association of Oral and Maxillofacial Surgeons of India

Fig. 85.2 Midface access, (a) Marking for a modified WeberFergusson incision respecting the nasal subunits. Lateral lower and upper eyelid extensions (for total maxillectomy with orbital exenteration) and medial glabella extension (for additional nasal access). Red

dotted lines with Lynch (superior) and crow's feet (lateral) extensions. (b) Exposure afforded by the incision. (c) Anterior ethmoid artery (arrow), exposed in the medial orbit along the frontoethmoid suture. (d) Lacrimal sac/nasolacrimal duct exposed in the lacrimal fossa 
cial" to the orbicularis oculi muscle in the eyelid region to preserve function, and it is important to avoid "button holes" in the thin skin of the eyelids.

Superior extension (Lynch [11] modification) can be incorporated, if additional access is required to the medial orbit and ethmoids (Fig. 85.2a). The nasal sidewall incision is extended superiorly along the medial orbit at least, $5 \mathrm{~mm}$ medial to the medial canthus, up to the medial end of the eye brow/medial supraorbital rim. The incision deepened down to the bone and the frontal process of the maxilla, anterior lacrimal crest and frontonasal suture exposed. The medial canthal tendon is "formally" identified and detached. It is "tagged" with a 3.0 Prolene suture on a round body needle, for subsequent reattachment. The medial orbit can now be exposed with fine periosteal elevators. The frontoethmoidal suture (FES) in the medial orbit provides an excellent landmark for the position of the anterior and posterior ethmoid vessels and optic canal. These vessels are identified along the suture, skeletonised and ligated/diathermised (Fig. 85.2c). The optic canal lies posteriorly in superomedial orbit, in line with the suture. The number of ethmoidal vessels varies frequently [1-3] and the over-reliance of the distances between the vessels ( $24 \mathrm{~mm}, 12 \mathrm{~mm}, 6 \mathrm{~mm}$ ) and the optic canal can be dangerous The FES can often lie "above" the cribriform plate, and its relationship to the anterior cranial fossa should be "critically assessed" in the preoperative scans. Osteotomies are best placed below the FES, if "unintentional" intracranial extension is to be avoided.

The lacrimal sac is identified inferiorly in the lacrimal fossa and can be dissected free for retraction or transection (Fig. 85.2d).

A medial extension, along the glabella skin crease, can be incorporated if additional access is required to the nasal bones, roof of the nasal cavity, or if a "nasal" swing is considered (Fig. 85.2a).

The lower eyelid extension can be combined with a similar upper eyelid incision, if a lid-sparing orbital exenteration is planned (Fig. 85.2a).

\subsubsection{Potential Complications and Solutions (Clinical Pearls)}

Unsightly scar: Use the modified Weber-Fergusson incision along the philtrum, nasal subunits with " $v$ " in the nasal floor and lip mucosa-meticulous layered closure in layers and accurate alignment of the vermillion border.

Delayed bone healing (maxillary swing): Minimal soft tissue elevations along the osteotomy sites, pre-plating prior to completion of osteotomy, use fine saw blades and bur and copious irrigation.

\section{Clinical Tips}

- Inject vasoconstrictor, make the incision in segments and use diathermy to minimise blood loss.

- Extend the midline skin incision past the vermillion, prior to incorporating the mucosal "V" to facilitate accurate approximation of the vermillion.

- Tattoo or mark the vermillion, if you feel it would help in later approximation.

- Intraoral incisions and the plane of dissection are dictated by the location of the tumour.

- If a lower eyelid extension is planned, the plane of dissection is ideally above the orbicularis oculi muscle (if eye is preserved).

- Soft tissue "elevation" is kept to the minimum along the osteotomy sites, if a maxillary swing is planned.

- Formal identification and tagging of the medial canthus are necessary for later reattachment.

- Recognise the "orientation" value of the frontoethmoidal suture.

- Beware of using distances between the ethmoidal foramina and optic canal as the "sole" modality during deep dissection of the medial orbit.

\subsection{Nasal Swing}

This provides access to the nasal cavity, ethmoids and nasal roof and can be considered for bilateral lesions, when the nasal skin/bones can be preserved. Currently, with the widespread use of endoscopic techniques, its role, as a "sole" access to these lesions, is restricted. It is often used for additional access, as part of a wider resection.

A modified Weber-Fergusson incision is made respecting the nasal subunits, and allowance is made for a transverse medial extension along the glabella skin crease (Fig. 85.3a). The soft tissues are retracted laterally and superiorly to obtain exposure of the nasal bones, frontal process of the maxilla and the piriform rims. The soft tissue overlying the nasal bone is left undisturbed. Exposure of the contralateral nasal bones is achieved by undermining in a subperiosteal plane. A fine bur/saw is used to make the bone cuts along the frontal process of the maxilla and across the nasal bones (Fig. 85.3b). The contralateral nasal osteotomy is carried out with fine osteotomes, if necessary, through separate stab incisions. The osteotomy sites are prelocalised with low-profile bone plates, removed and replaced during the procedure. The underlying nasal mucosa and soft tissue along the piriform rim are released with a diathermy. The soft tissue incisions and the bone cuts are stepped or staggered. 
The nasal septum restricts complete lateral retraction. The septal cartilage is transected with a cutting diathermy-the damp tonsil swab in the other nostril can prevent accidental injury to the contralateral lateral nasal wall mucosa and the facial skin. The $1 \mathrm{~cm}$ strut of nasal septal cartilage is preserved along the dorsum and columella to prevent collapse (Fig. 85.3c). The nasal bones and the soft tissues can now be retracted to the opposite side (Fig. 85.3d).
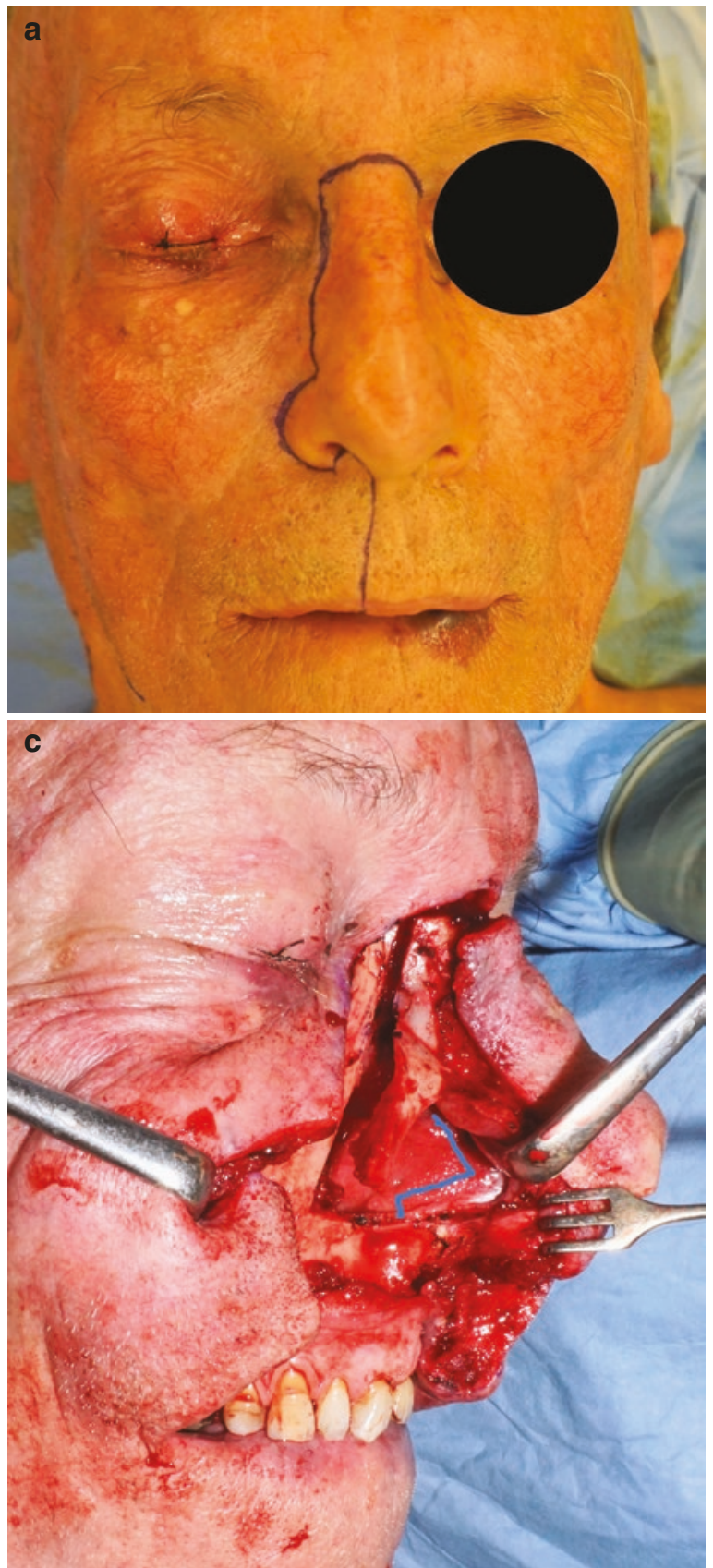

CAssociation of Oral and Maxillofacial Surgeons of India

Fig. 85.3 Nasal swing. (a) Skin marking, respecting the nasal sub units. (b) Bone cuts along the frontal process of the maxilla and nasal bones. (c) Marking for septal incision preserving dorsal and caudal strut. (d) Exposure of the nasal cavity following retraction of the nose.
A soft tissue only and soft and hard tissue nasal swing can be combined with a larger midface/craniofacial resection for pathologies involving adjacent structures. The nasal swing can be linked with a frontal craniotomy for resection of tumours that also involve the central compartment of the anterior cranial fossa (Fig. 85.3e, f).

The plates are replaced, and the wound is closed in layers (Fig. 85.3g).

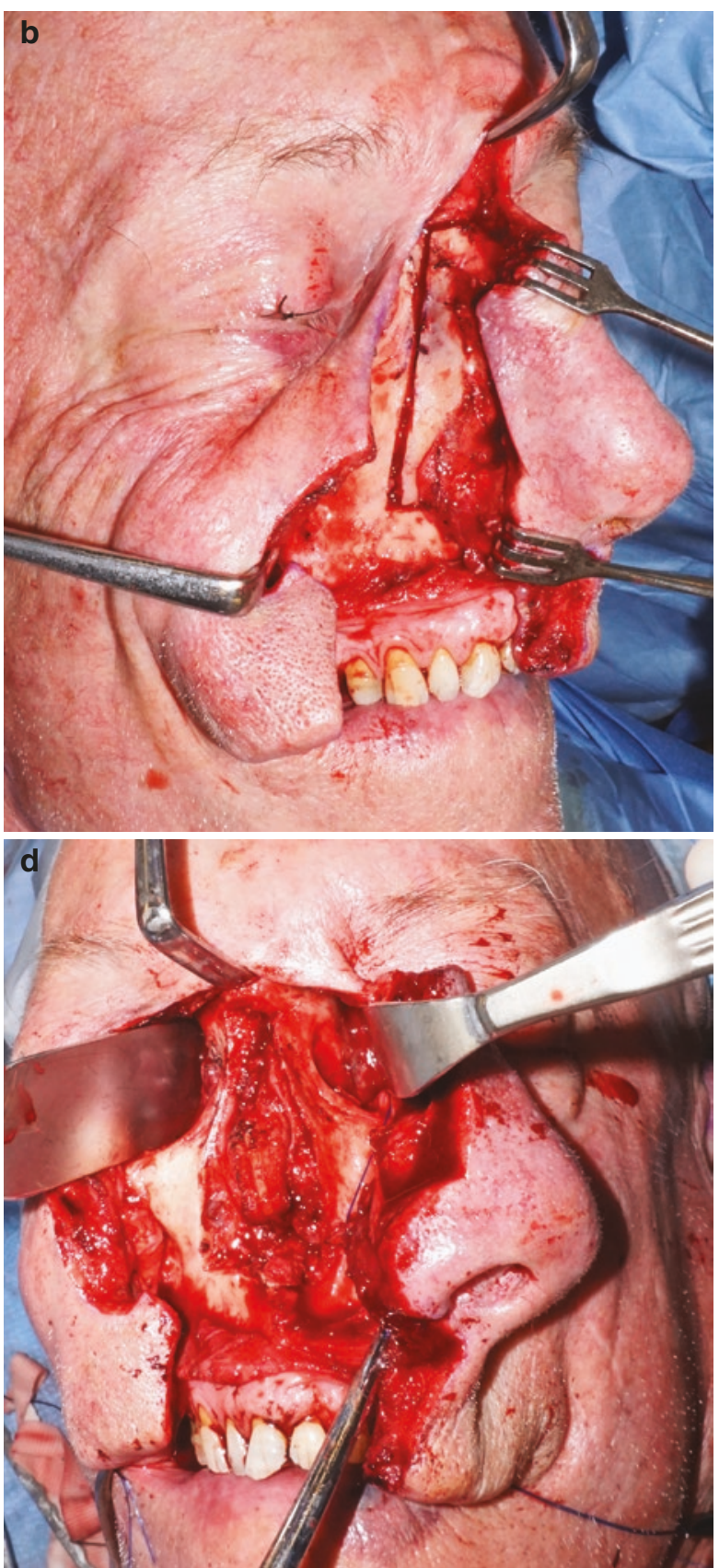

(e) Bone cuts for "nasal/ethmoid clearance" as a part of a craniofacial resection. (f) Defect viewed from the cranial aspect following "nasal/ ethmoid" clearance. (g) Wound closure following nasal swing 

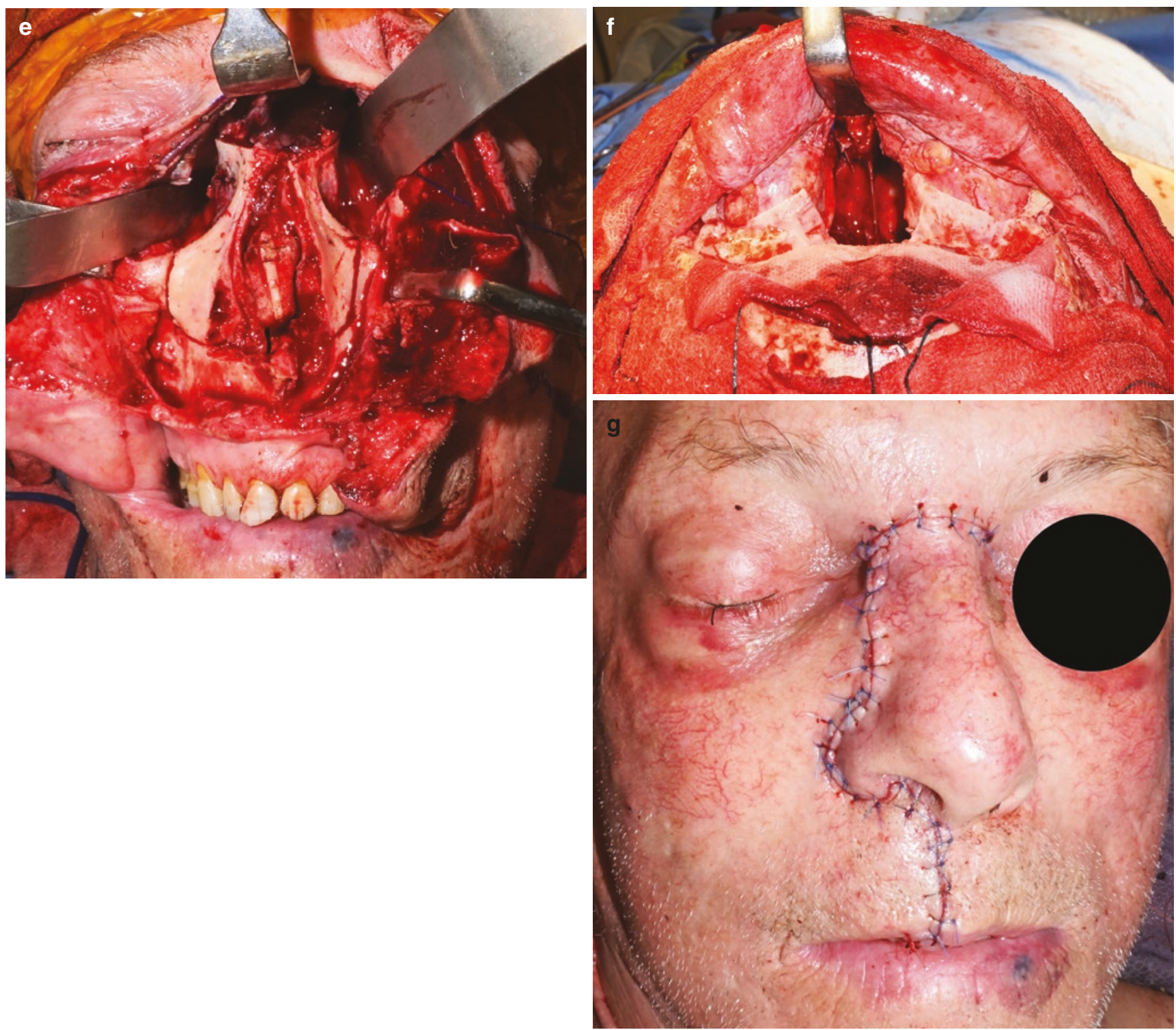

CAssociation of Oral and Maxillofacial Surgeons of India

Fig. 85.3 (continued)

\subsubsection{Potential Complications and Solutions (Clinical Pearls)}

Unsightly scar: Use the modified incision along the philtrum, nasal subunits with " $\mathrm{v}$ " in the nasal floor and lip mucosa. Carry out meticulous closure in layers and acheive accurate approximation of the vermillion border.

Delayed bone healing (nasal osteotomy): Minimal soft tissue elevations along the osteotomy sites, pre-plating prior to completion of osteotomy, use fine saw blades, burs and osteotomes and copious irrigation.

Nasal collapse: Attempt to preserve caudal/dorsal septal strut.

\section{Clinical Tips}

- The soft tissue dissection is kept to the minimum, overlying the nasal bones.

- The osteotomy is planned along the frontal process of the maxilla, which is mobilised along with the nasal bones.

- Create a contralateral subperiosteal pocket and use "stab" incisions and fine osteotomes to complete the osteotomy.

- Pre-plate the osteotomies prior to completion.

- Preserve at least a $1 \mathrm{~cm}$ caudal and dorsal strut of septum to prevent nasal collapse. 


\subsection{Per Oral Access}

A significant proportion of the oral lesions can be accessed and managed per orally. The use of a solely per oral access is dictated by the location and size of the lesion, the mouth opening and status of the dentition. An appropriately sized mouth prop/gag with cheek and tongue retractors and traction sutures can be utilised to provide the necessary access to safely carry out the procedure (Fig. 85.4).

\section{Clinical Tips}

- Utilise appropriate retraction to obtain the "best" access.

- "Orthodontic" cheek retractors can be very helpful for additional retraction and protecting the commissures.

- If teeth extractions are planned, these are best carried out prior to the resection to improve access.

\subsection{Soft Tissue Lip Split}

Lip split incisions to gain additional access to the oral cavity have been in practice for over 150 years. A midline chin incision was described by Roux [17] and subsequently popularised by Trotter [18] in the early 1900s. Further modifications by Macgregor [19] placed the chin component along the mentolabial fold, and Hayter [20] suggested incorporating a chevron in the vermillion and mentolabial area.

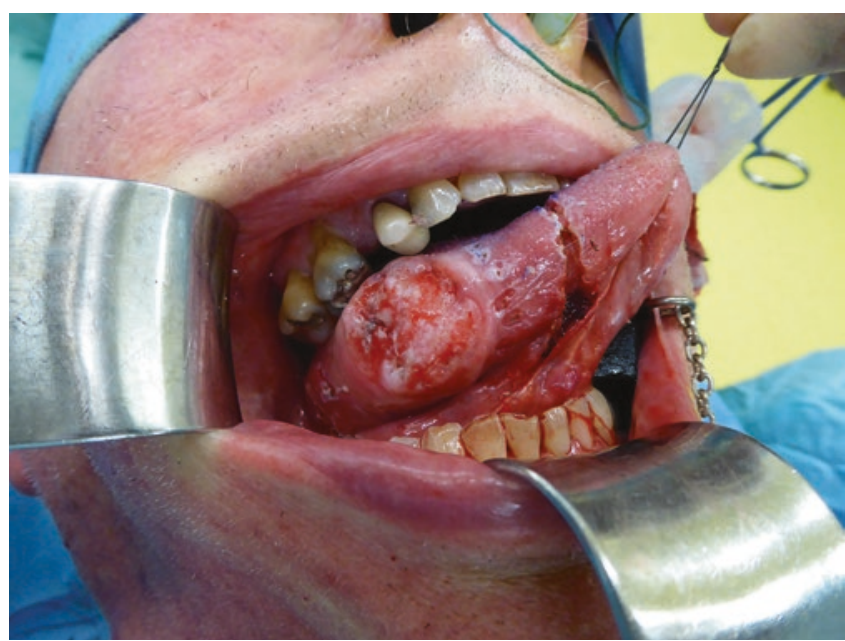

CAssociation of Oral and Maxillofacial Surgeons of India

Fig. 85.4 Per oral access. Per oral access for excision of a tongue lesion
Soft tissue only lip split can provide excellent access to the posterior buccal mucosa and mandible, for lesions that cannot be safely excised through a per oral or cervical approach. The principle disadvantage of this approach is the need for lip split scar and likely sacrifice the mental nerve; this must be weighed against improved access. The latter is not a consideration if the inferior alveolar nerve has to be sacrificed in the subsequent resection. A lip split through the commissure would have to be considered for tumours located close to the commissure to avoid devascularising the segment between the midline lip split and commissure. This would also be a consideration for composite resections involving the adjacent skin.

A full-thickness vertical incision is made through the lower lip in the midline and extended inferiorly along the midline of the chin/upper neck (Fig. 85.5a). It continues with an appropriately placed low-neck skin crease incision. A "V" can be incorporated in the mucosal aspect of the lower lip to facilitate accurate approximation. The cosmetic outcome with a midline chin incision is excellent and reduces the risk of numbness and ischemia of the ipsilateral chin, associated with a curvilinear incision along the mental fold.

The neck skin flap is raised in a plane deep to the platysma, up to the lower border of the mandible, taking care to avoid injury to the marginal mandibular branch of the facial nerve. The cheek flap is elevated by detaching the platysma from the lower border of the mandible in the subperiosteal plane. More posteriorly, the dissection can be continued superficial or deep to the masseter muscle (Fig. 85.5b).

Intraoral soft tissue incisions are placed along the gingival crevice or the lower vestibule and are principally determined by the location of the tumour. The wound is meticulously closed in layers, taking care to accurately align the vermillion border.

\subsubsection{Potential Complications and Solutions (Clinical Pearls)}

Unsightly scar: Accurate alignment of the vermillion border and meticulous layered closure.

Mental and marginal mandibular nerve damage: Appropriate plane of dissection and identification and protection of the nerves.

Lip necrosis: Avoid "additional" midline incision for tumours in the commissure region or composite buccal mucosa resections. 


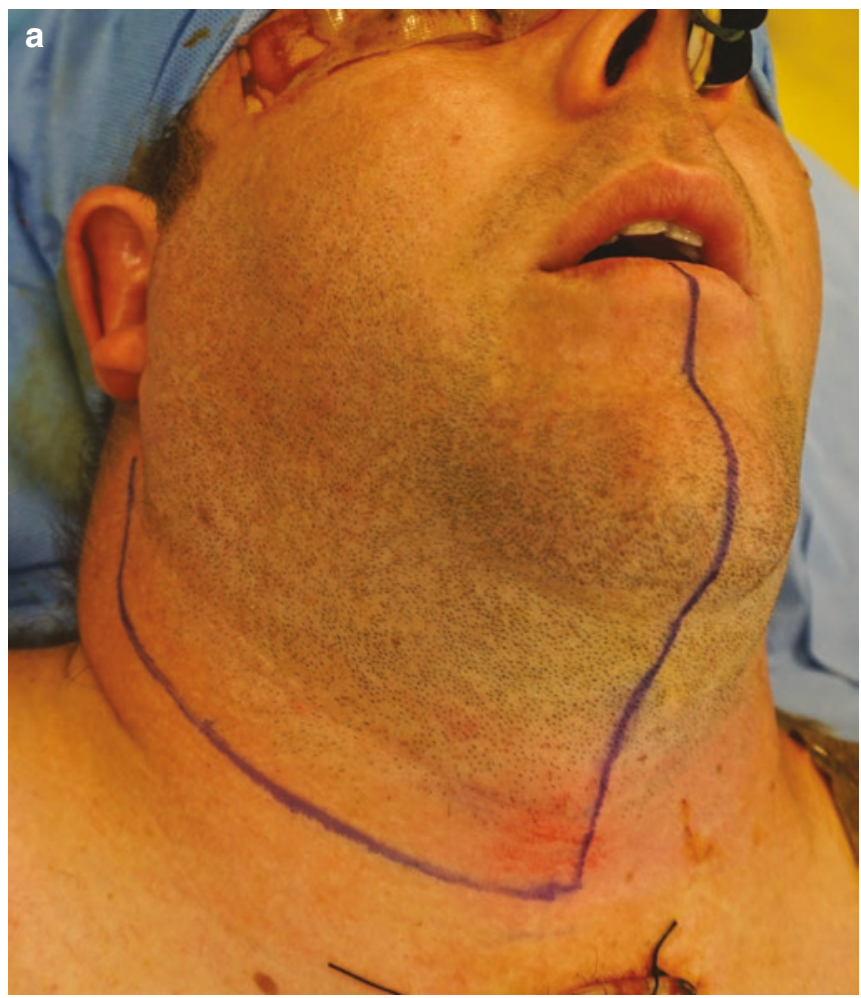

CAssociation of Oral and Maxillofacial Surgeons of India

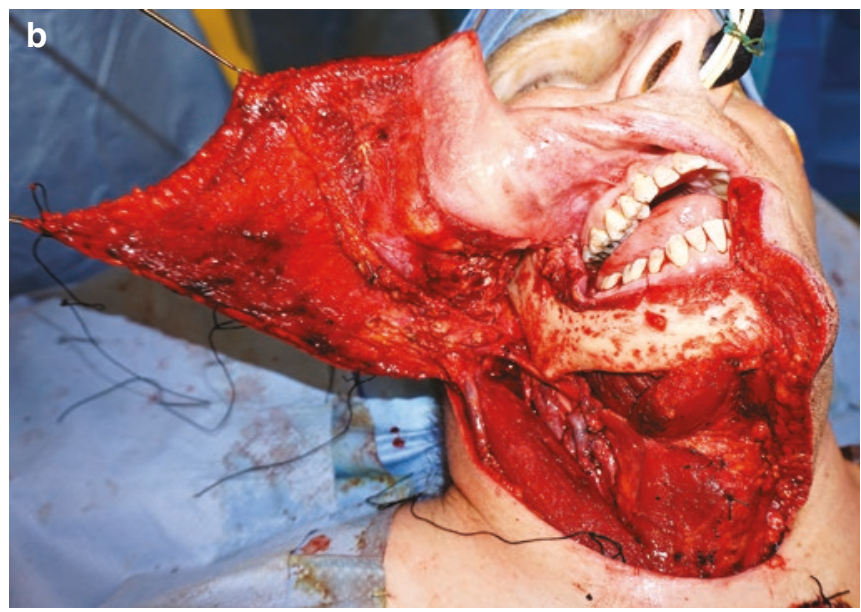

Fig. 85.5 Soft tissue lip split. (a) Skin markings for a soft tissue lip split. (b) Exposure following flap elevation

\section{Clinical Tips}

- Dissection of the anterior mandible is in the subperiosteal plane to minimise injury to the facial and mental nerves.

- Identify the mental nerve and decide if it can be preserved, prior to sacrificing it.

- More posteriorly, the dissection can be superficial or deep to the masseter muscle. If superficial dissection is planned, care must be exercised to prevent injury to the facial nerve branches and parotid duct.

- Avoid midline lip split for tumours adjacent to the commissure and composite resections.

\subsection{Visor Flap}

A visor flap can be utilised for lesions in the floor of mouth, tongue and mandible and can be combined with bilateral neck dissections. The incision is marked at an appropriate low-neck skin crease and extends from one mastoid tip process to the other (Fig. 85.6a). The skin flaps are raised in the sub-platysmal plane up to the lower border of the mandible, taking care to avoid injury to the marginal mandibular branch of the facial nerve. The periosteum is incised along the lower border of the mandible and a mucoperiosteal flap elevated, taking care to identify the mental nerves. Intraoral mucosal incisions are determined by the location of the lesion, and the mental nerves might have to be sacrificed to obtain further access or adequate margins. The skin flaps are retracted cephalad with "penrose" rubber drains (Fig. 85.6b).

When used as a part of lingual release/pull-through procedure to access a floor of mouth/tongue lesion, the mental nerves and labial/buccal soft tissue can be left undisturbed $[21,22]$. Resection of the lesions in the anterior floor of mouth along with the mandible results in detachment of the tongue to the mandible. It is essential that the geniohyoid and genioglossus muscles are reattached to the reconstructed mandible to prevent the tongue from falling back. The wound is closed in layers. An advantage of the visor incision is the avoidance of a lip split facial scar, which needs to be weighed against the risk of bilateral injury to the marginal mandibular branch of the facial and mental nerves.

\subsubsection{Potential Complications and Solutions (Clinical Pearls)}

Mental and marginal mandibular nerve damage: Appropriate plane of dissection and identification and protection of the nerves. 

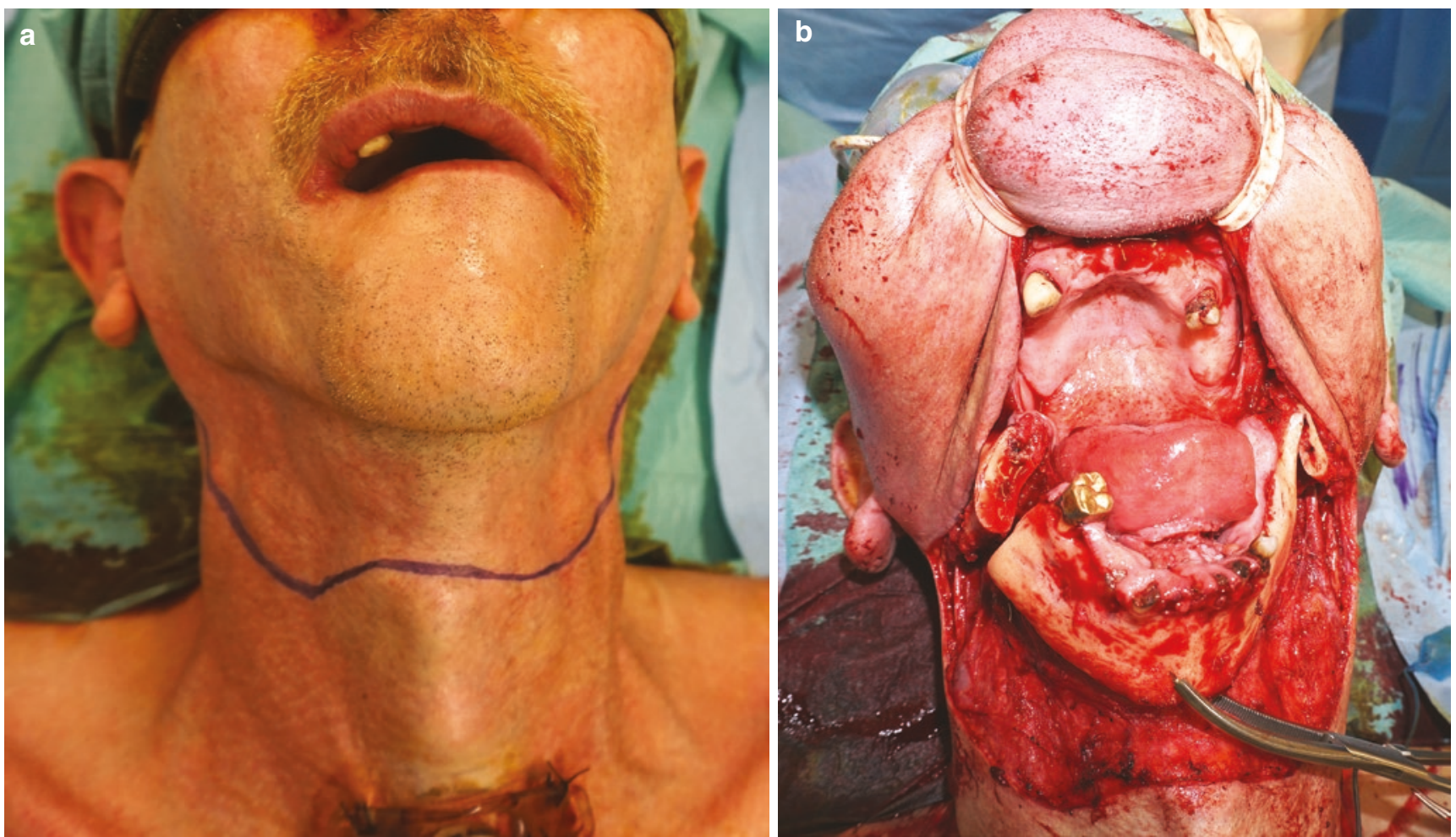

CAssociation of Oral and Maxillofacial Surgeons of India

Fig. 85.6 Visor flap. (a) Skin markings for a visor flap. (b) Exposure following flap retraction with "penrose" rubber drains

\section{Clinical Tips}

- Expose the mandible in the subperiosteal plane to identify the mental foramen and minimise damage to the facial nerve.

- The intraoral labial/buccal vestibular incision is determined by the location of the tumour and can be placed along the vestibule or crevicular margins.

- If the tongue and the hyoid apparatus is detached from the anterior mandible, the remnant genioglossus and geniohyoid should be "formally" suspended to the (reconstructed) mandible with non-resorbable sutures.

\subsection{Transmandibular Approaches}

\subsubsection{Mandibular Swing}

\subsubsection{Lip Split Paramedian Mandibulotomy}

Mandibulotomy to access oral cavity, oropharynx and skull base has been in use for over 150 years, since its initial description by Roux [17] and Trotter [18]. It was popularised by Spiro [23], who suggested a median mandibulotomy, and McGregor [19] described a paramedian location, anterior to the mental foramen. Though various sites and design of the osteotomy have been described, a straight line paramedian mandibulotomy is currently the most widely used option, as it preserves the attachment of the anterior belly of the digastric, geniohyoid and genioglossus muscles and mental nerve. The availability of rigid fixation and fine saws negate the need for step osteotomies and tooth extractions in most cases.

The lip split with a mandibulotomy provides excellent access to the mid and posterior third of the tongue, floor of the mouth, soft palate, tonsillar fossa, oropharynx/posterior pharyngeal wall and supraglottic larynx. It can be extended posteriorly to provide additional access to the infratemporal fossa and the parapharyngeal space with safe vascular control. It can be considered in three discrete stages; lower lip/ chin division, paramedian mandibulotomy and soft tissue elevation on the lingual aspect of the mandible.

A vertical full-thickness incision is made through the midline of the lower lip and extended inferiorly across the midline of the chin/upper neck and continues with an appropriately placed low-neck skin crease incision (Fig. 85.7a). A "V" can be incorporated in the mucosal aspect of the lower lip to facilitate accurate approximation.

The cosmetic outcome with a midline chin incision is excellent and reduces the risk of numbness and ischemia of the ipsilateral chin, associated with a curvilinear incision along the mental fold.

The neck skin flap is raised in a plane deep to the platysma, up to the lower border of the mandible, taking care to avoid injury to the marginal mandibular branch of the facial nerve. Intraorally, the incision through the labial mucosa and 

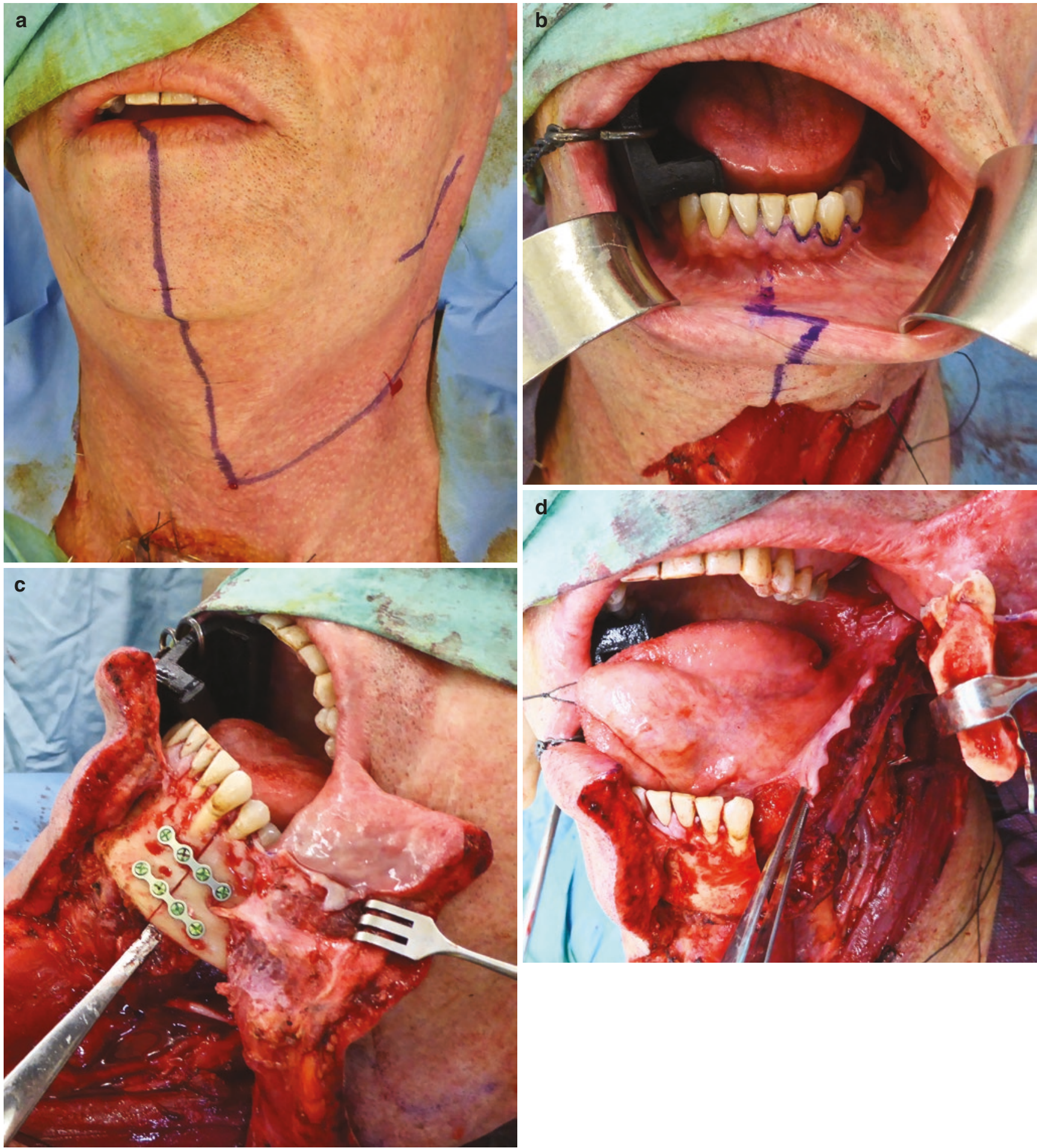

CAssociation of Oral and Maxillofacial Surgeons of India

Fig. 85.7 Lip split paramedian mandibulotomy. (a) Skin marking for lip split mandibulotomy. (b) Mucosal marking for lip split mandibulotomy. (c) Lingual subperiosteal tunnel, bone cuts and pre-plating prior to completion of mandibulotomy. (d) Lingual crevicular incision and

mandible retracted laterally following release of mylohyoid muscle. (e) Additional exposure of the infratemporal fossa by tracing the inferior dental and lingual nerves. Defect following maxillectomy and infratemporal fossa clearance (different patients) 


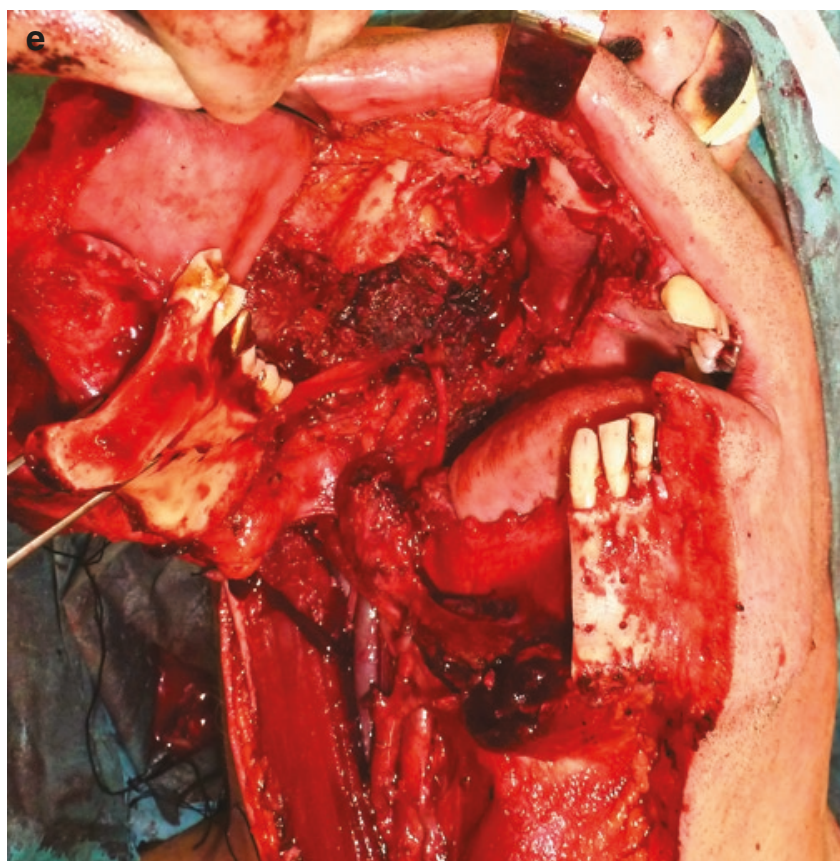

CAssociation of Oral and Maxillofacial Surgeons of India

Fig. 85.7 (continued)

attached gingiva is designed (stepped), so that it does not directly overlie the planned osteotomy (Fig. 85.7b). The elevation of the periosteum and mentalis muscle should be restricted to allow identification and protection of the mental nerve and placement of the plates.

A soft tissue pocket is created by elevating the lingual mucosa off the mandible adjacent to the osteotomy. A periosteal elevator is placed in the pocket, and an osteotomy is carried out between the lower lateral incisor/canine or canine/first premolar region (Fig. 85.7c). The mandible is osteotomised with a fine saw, taking care to avoid injury to the tooth roots. Occasionally a tooth would have to be removed to facilitate the osteotomy. The mandible is pre-plated prior to completion of the bone cuts, and these are removed and replaced during the procedure. The osteotomy cuts are in a straight line, as a stepped osteotomy neither aids fixation or bone union and can increase the risk of injury to the teeth apices and mental nerve.

Once the mandible is divided, it is gently retracted laterally, and an incision made along the lingual gingival crevice and the mucoperiosteum elevated off the lingual mandible (Fig. 85.7d). The mylohyoid muscle is detached along its attachment to the mylohyoid ridge. Further soft tissue dissection is dictated by the location of the tumour.

If additional access is required to the infratemporal fossa/ parapharyngeal space, it will be necessary to detach the medial pterygoid muscle from the medial ramus of the mandible. In addition, the stylomandibular ligament (at the angle of the mandible) and the sphenomandibular ligament (at the lingula) have to be detached to obtain the best possible access (Fig. 85.7e). The inferior dental and lingual nerve are identified early and protected and can be utilised as roadmaps to the foramen ovale and skull base. The maxillary artery can also be identified entering the infratemporal fossa, at the neck of the condyle by following the posterior border of the mandible. Early identification and ligation can help provide a relatively bloodless field for dissection of the infratemporal fossa.

The lingual gingival crevicular incision facilitates easy closure and avoids placement of the suture line at the depth (sump) of the wound. The mandible is held in occlusion, and the plates are replaced accurately to achieve the premorbid localisation. The wound is meticulously closed in layers.

\subsubsection{Potential Complications and Solutions (Clinical Pearls)}

Unsightly scar: Accurate alignment of the vermillion and meticulous layered closure.

Mental and marginal mandibular nerve damage: Appropriate plane of dissection and identification and protection of the nerves.

Delayed bone healing: Minimal soft tissue elevations along the osteotomy sites, pre-plating prior to completion of osteotomy, use fine saw blades, burs, osteotomes and copious irrigation. Osteotomy ideally in the canine region.

Damage to adjacent teeth: Design osteotomy where space allows, use fine instruments and consider extraction.

\section{Clinical Tips}

- A straight osteotomy in the canine region is ideal and the site pre-plated prior to completion of the bone cuts.

- The soft tissue incision and bone osteotomies are stepped, so that they do not lie on the same plane.

- The lingual soft tissues are retracted following a lingual crevicular incision.

- The medial pterygoid muscle and stylomandibular and sphenomandibular ligaments have to be detached to obtain addition access to the infratemporal fossa.

- The lingual and inferior dental nerves provide excellent landmarks and can be utilised as roadmaps to the skull base and foramen ovale.

- The maxillary artery should be identified at the neck of the condyle, as it enters the infratemporal fossa and ligated early in the procedure to minimise blood loss and improve visibility during infratemporal fossa clearance. 

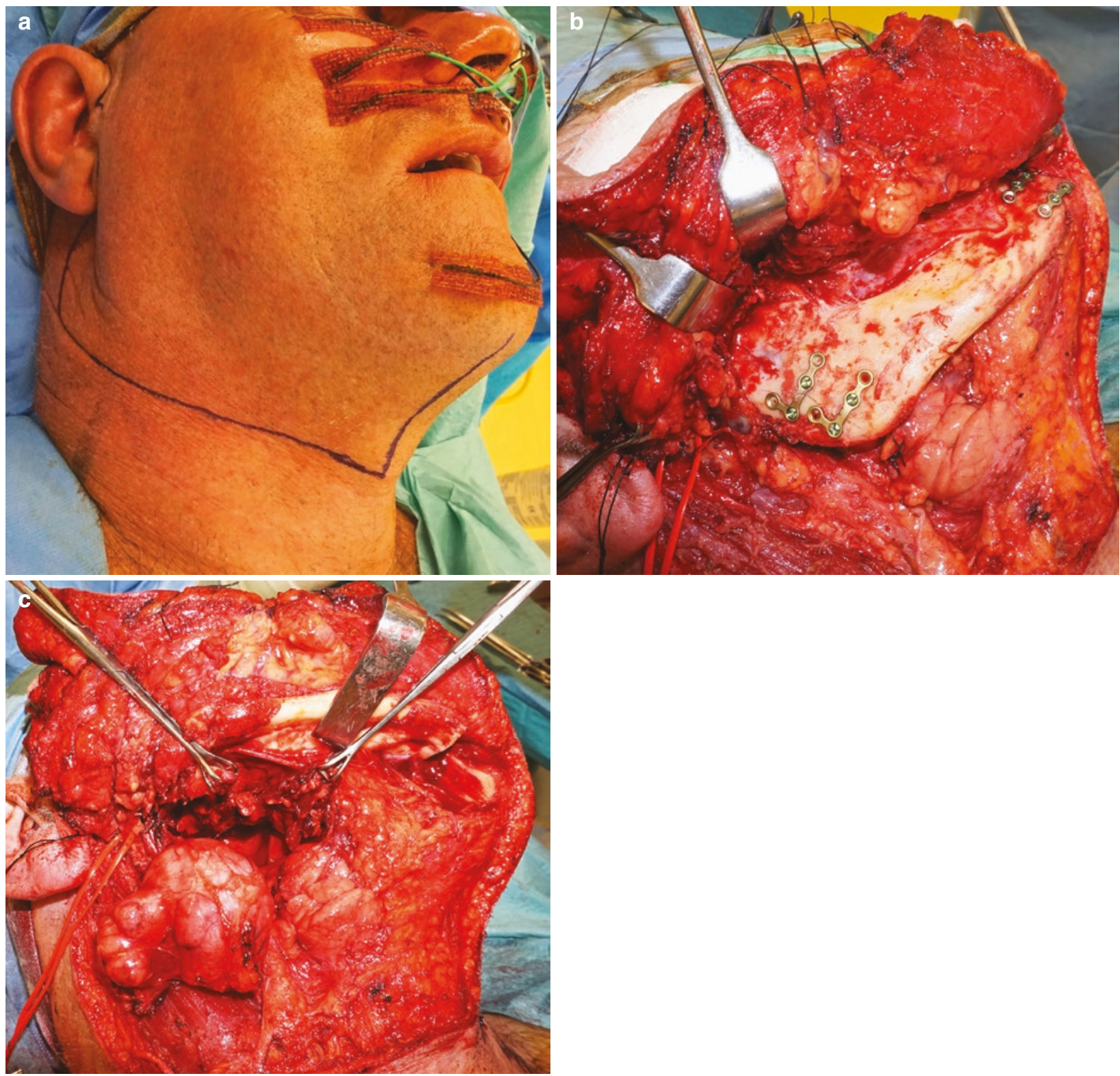

CAssociation of Oral and Maxillofacial Surgeons of India

Fig. 85.8 Double mandibular osteotomy. (a) Skin markings for double mandibular osteotomy. (b) Bone cuts marked and mandible pre-plated. (c) Mandibular segment retracted laterally and superiorly to expose deep lobe parotid tumour

\subsection{Double Mandibular Osteotomy}

Mandibular osteotomies to access the parapharyngeal region can be broadly divided into those involving the oral cavity (lip split mandibulotomy) and those staying out with the oral cavity. Since it was initially popularised by Attia [24] to access parapharyngeal and pterygomaxillary region, several designs of osteotomies have been described, involving one, two and three osteotomies, variously placed in the paramedian and ramus/condylar region [25].

Double mandibular osteotomy provides excellent access to the infratemporal fossa, parapharyngeal space, deep lobe of the parotid and terminal extracranial internal carotid artery adjacent to the skull base, when the oral cavity does not have to be entered.

A low-neck skin crease incision with submental extension is made (Fig. 85.8a), and the neck flap is raised in the subplatysmal plane up to the lower border of the mandible, preserving the marginal mandibular branch of the facial nerve. The lateral mandible is exposed in a subperiosteal plane and the mental nerve identified and protected anteriorly. The masseter muscle is detached from the lateral ramus of the mandible up to the sigmoid notch. The anterior bone cuts are fashioned anterior to the mental foramen, between the canine/ lateral incisor or canine/first premolar teeth roots. The posterior bone cut is made from the sigmoid notch to the lower 
border of the mandible, posterior to the lingula and inferior dental canal (similar to a vertical sub-sigmoid osteotomy). The mandible is pre-plated prior to completion of the bone cuts (Fig. 85.8b). The plates are removed and replaced during the procedure. Following completion of the osteotomy, the segment of the mandible containing the inferior dental nerve is retracted lateral and superiorly to provide wide access to the parapharyngeal and infra temporal areas (Fig. 85.8c).

Further soft tissue dissection is dictated by the necessity to access specific parts of the medial mandibular area.

The stylomandibular ligament can be detached from the posterior "condylar" segment to obtain further exposure of the stylomastoid area. The muscular and ligamentous attachments to the styloid process can be detached, and, if necessary, the styloid process is osteotomised to gain addition access to the "post-styloid" space, terminal extracranial internal carotid and the skull base close to the jugular foramen and lower cranial nerves.

This procedure avoids a lip split scar and helps preserve sensation to the lip while providing access to the more "difficult-to-reach" areas.

\subsubsection{Potential Complications and Solutions (Clinical Pearls)}

Mental and marginal mandibular nerve damage: Appropriate plane of dissection and identification and protection of the nerves. Osteotomies planned to avoid the course of the inferior dental nerve.

Delayed bone healing: Pre-plating prior to completion of osteotomy, use fine saw blades, burs, osteotomes and copious irrigation.

Damage to adjacent teeth: Design osteotomy where space allows, use fine instruments and consider extraction.

\section{Clinical Tips}

- This procedure is considered when intraoral access is "not" required.

- A lip split scar is avoided.

- The lateral mandible is exposed in the subperiosteal plane, and the mental and facial nerve branches are protected.

- The bone cuts are made anterior to the mental foramen and posterior to the mandibular foramen and inferior dental canal.

- The osteotomy site is pre-plated prior to completion of the bone cuts.

- Styloid process and its' attachments can be detached to gain addition access to the post styloid and "stylomastoid" spaces.

\subsection{Zygomatic Osteotomy}

Facial translocation techniques allow modular craniofacial disassembly of the facial skeleton to access "relatively" inaccessible regions of the skull base and nasopharynx. A variety of osteotomies have been described, but with the increased use of endoscopic approaches, the necessity for extensive procedures continues to diminish. Various modifications of zygomatic and orbital osteotomies in combination with craniotomies has been described since it was popularised by Lesoin [26], Hakuba [27] and Sindou [28] to access skull base lesions.

Zygomatic osteotomy, pedicled on the masseter muscle and its subsequent inferior displacement, provides simultaneous exposure of the temporal and infratemporal fossa and orbit. An additional frontotemporal craniotomy can link the middle and anterior cranial fossa and the middle cranial fossa with the infratemporal fossa. The extent of the "zygomatic" osteotomy and the direction of retraction of the temporalis is determined by the location of the pathology. For subcranial lesions, (temporal/infratemporal fossa/orbit), the temporalis is retracted superiorly following a coronoidectomy. For simultaneous exposure of the anterior/middle cranial fossa and temporal/infratemporal fossa/orbit, the temporalis is reflected inferiorly. The vascularity of the temporalis muscle can be at risk with both superior and inferior retraction.

The zygomatic body, arch and lateral and inferior orbital rims are exposed via a coronal flap (Fig. 85.1e, g). Meticulous subperiosteal orbital dissection is carried out to protect the orbital contents, which are retracted with thin malleable retractors. The temporalis is detached from the lateral orbit in the temporal fossa. The lateral end of the inferior orbital fissure is identified in the temporal fossa and orbit with a blunt hook. The bone cuts are made with a fine saw: superiorly at the frontozygomatic suture, infero-laterally from the lateral infraorbital rim through the body of the zygoma towards the inferior orbital fissure and posteriorly just anterior to the articular eminence. A sagittal bone cut is then made in the lateral orbital wall from the temporal fossa aspect, extending from the frontozygomatic suture osteotomy to the inferior orbital fissure (Fig. 85.9a). A more limited zygomatic arch osteotomy can be utilised, when orbital access is not required (Fig. 85.9b). The osteotomy is preplated, and plates are removed and replaced during the procedure (Fig. 85.9b). The cuts are completed, and the zygoma is mobilised and pedicled inferiorly on the masseter muscle.

Exposure to the infratemporal fossa is limited with a zygomatic osteotomy, which restricts its use to benign pathology, when utilised as a sole means of access. It can however be combined with frontotemporal craniotomy to widely access the anterior and middle cranial fossa, optic canal, superior orbital fissure and for combined middle cranial/infratemporal fossa resections (Figs. $85.1 \mathrm{~h}$ and $85.9 \mathrm{c}$ ). 

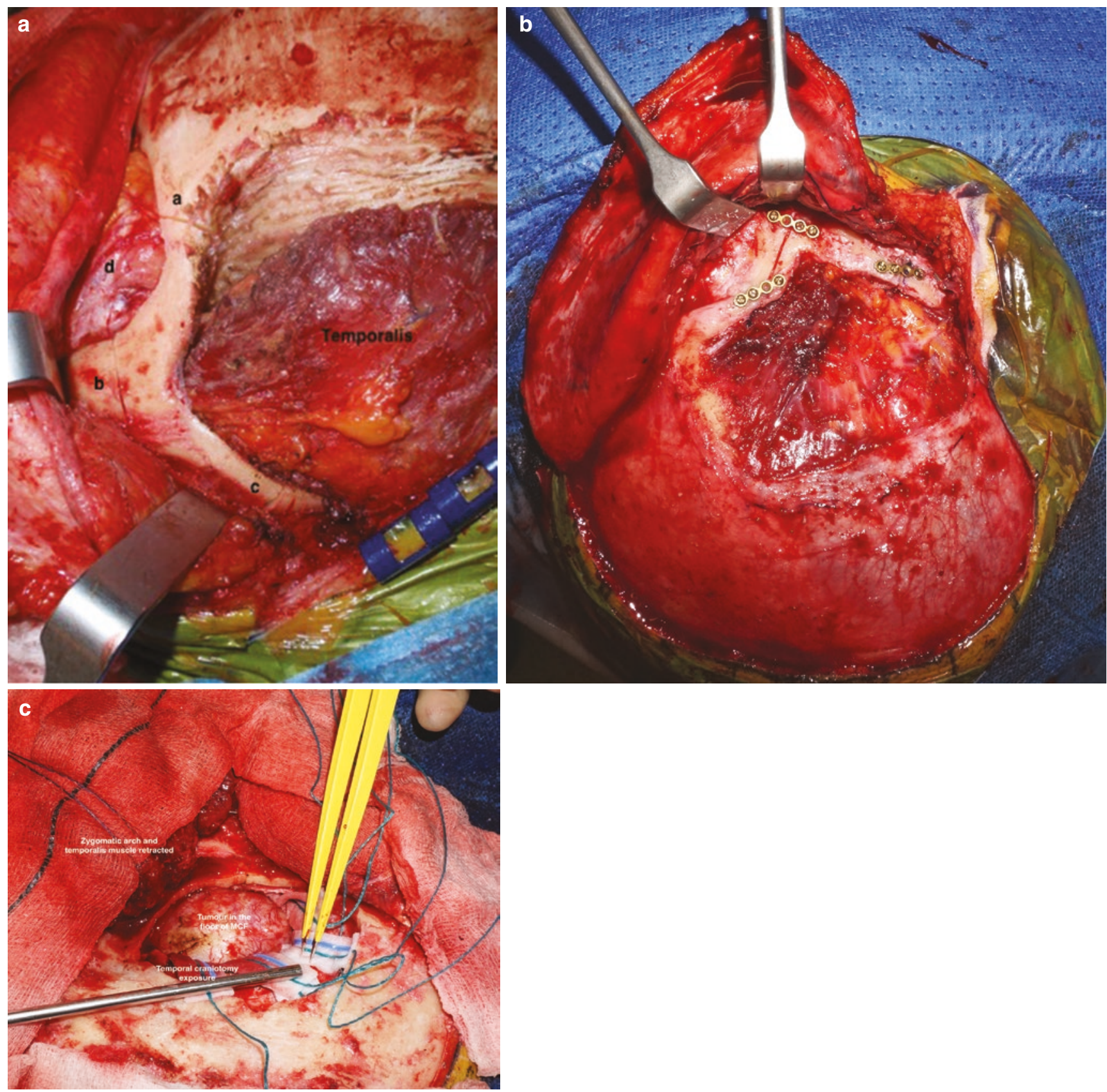

CAssociation of Oral and Maxillofacial Surgeons of India

Fig. 85.9 Zygomatic osteotomy. (a) Bone cuts marked for a zygomatic osteotomy. (a) Osteotomy above frontozygomatic suture, (b) osteotomy across body of zygoma, (c) osteotomy across zygomatic arch and (d) orbital contents. (b) Bone cuts marked and pre-plated for zygomatic

\subsubsection{Potential Complications and Solutions (Clinical Pearls)}

Delayed bone healing: Preserve masseter attachment, preplating prior to completion of osteotomy, use fine saw blades, burs, osteotomes and copious irrigation. arch osteotomy (extended to lateral orbital rim due to increased width of orbital rim). (c) Tumour exposed in the floor of the middle cranial fossa following temporal craniotomy and retraction of the zygomatic arch and temporalis

Damage to orbital contents: Meticulous intra-orbital subperiosteal dissection and haemostasis, fine malleable retractors for orbital retraction and bone cuts under "direct" vision.

Malposition of lateral canthus: Accurate bone reapproximation with pre-plating. Consider tagging lateral canthus prior to detachment and subsequent reattachment. 


\section{Clinical Tips}

- The lateral limit of the inferior orbital fissure in the orbit and temporal fossa is an important landmark for orbital and zygomatic osteotomies. A "blunt hook" can help with its safe identification.

- The extent of the osteotomy is determined by the location of the lesion and the need to enter the orbit.

- The attachment of the masseter muscle to the osteotomised zygomatic complex should be preserved.

- The osteotomy along the zygomatic arch should be made anterior to the articular eminence, to avoid disturbing the temporomandibular joint.

- The osteotomy sites are pre-plated, prior to completion of the bone cuts.

- Trismus is often expected and can be minimised by jaw opening exercises.

\subsection{Lateral and Superior Orbitotomies}

Lateral orbitotomy was initially popularised by Kronlein [29] but with a reverse "C"'-shaped incision overlying the temple. A variety of modifications, principally in the design of the skin incisions, have been described subsequently: lateral canthotomy $[30,31]$ "S"-shaped incision over the orbital rim, upper eyelid skin crease incision and coronal flap.

Superior/lateral orbitotomies, combined with frontal [32] and pterional [33] craniotomies have been extensively used since their original descriptions in the 1980s.

This approach is useful for lacrimal and lateral/superior/ inferior extra and intraconal orbital lesions and provides additional access for "lookup" approaches to the anterior and middle cranial fossa and for reconstruction with a temporalis flap following orbital exenteration.

A coronal flap is raised, and the zygomatic complex is exposed as described above for the zygomatic osteotomy (Fig. 85.10a). For isolated lesions, a Stallard-Wright [31] " $\mathrm{S}$ "-shaped incision extending from the eyebrow, inferolaterally over the lateral orbital rim to the crow's feet skin crease or an upper eyelid skin crease, can be utilised (Fig. 85.10b). The temporalis muscle is reflected posteriorly to expose the temporal aspect of the lateral orbit, and the orbital periosteum (periorbita) is elevated from lateral orbital wall (Fig. 85.10c). The lateral end of inferior orbital fissure is identified with a blunt hook, both within the orbit and the temporal fossa. Perforating blood vessels are identified and coagulated prior to division.

The orbital contents are protected with a malleable retractor, and the bone cuts are made with a thin saw. Superiorly, just above the frontozygomatic suture; inferiorly, inferior lateral orbital rim along the superior border of the zygomatic arch (the superior border of the zygomatic arch is at the same level as the orbital floor) up to the lateral limit of inferior orbital fissure.

The posterior cut is made with a fine bur/piezo saw in the lateral orbital wall, joining the superior bone cut to the lateral limit of the inferior orbital fissure. This is more easily made from the temporal aspect. The bone cuts are pre-plated prior to removal of the osteotomised segment and plates replaced following completion of the procedure.

The lateral orbitotomy can be combined with a superior orbitotomy and is usually performed in conjunction with a frontotemporal craniotomy. The craniotomy is best performed initially, and the superior orbital wall is delineated from the cranial aspect. With malleable retractors in situ, the superior and lateral orbitotomy can be carried out under direct vision (Fig. 85.10d). This provides excellent exposure of the contents of the superior orbit, superior orbital fissure and optic nerve/canal (Fig. 85.10e). This can also be used for "lookup" approaches to the superior anterior and middle cranial fossa lesions. The bone flaps are replaced (Fig. 85.10f), and the wounds are closed in layers. The medial extent of the superior orbitomy can be limited by the extent of the frontal sinus. The supraorbital neurovascular bundle will have to be protected/retracted.

\subsubsection{Potential Complications and Solutions (Clinical Pearls)}

Delayed bone healing: Pre-plating prior to completion of osteotomy, use fine saw blades, burs, osteotomes and copious irrigation.

Damage to orbital contents: Meticulous intra-orbital subperiosteal dissection and haemostasis, fine malleable retractors for orbital retraction and bone cuts under "direct" vision.

Malposition of lateral canthus: Accurate bone reapproximation with pre-plating. Consider tagging lateral canthus prior to detachment and subsequent reattachment.

\section{Clinical Tips}

- The lateral limit of the inferior orbital fissure in the orbit and temporal fossa is an important landmark for orbital and zygomatic osteotomies. A "blunt hook" can help with its safe identification.

- The extent of the osteotomy is determined by the location of the lesion.

- The superior surface of the zygomatic arch is in line with the orbital floor and is a useful landmark for bone cuts in the lateral orbital rim.

- The osteotomy sites are pre-plated prior to completion of the bone cuts. 

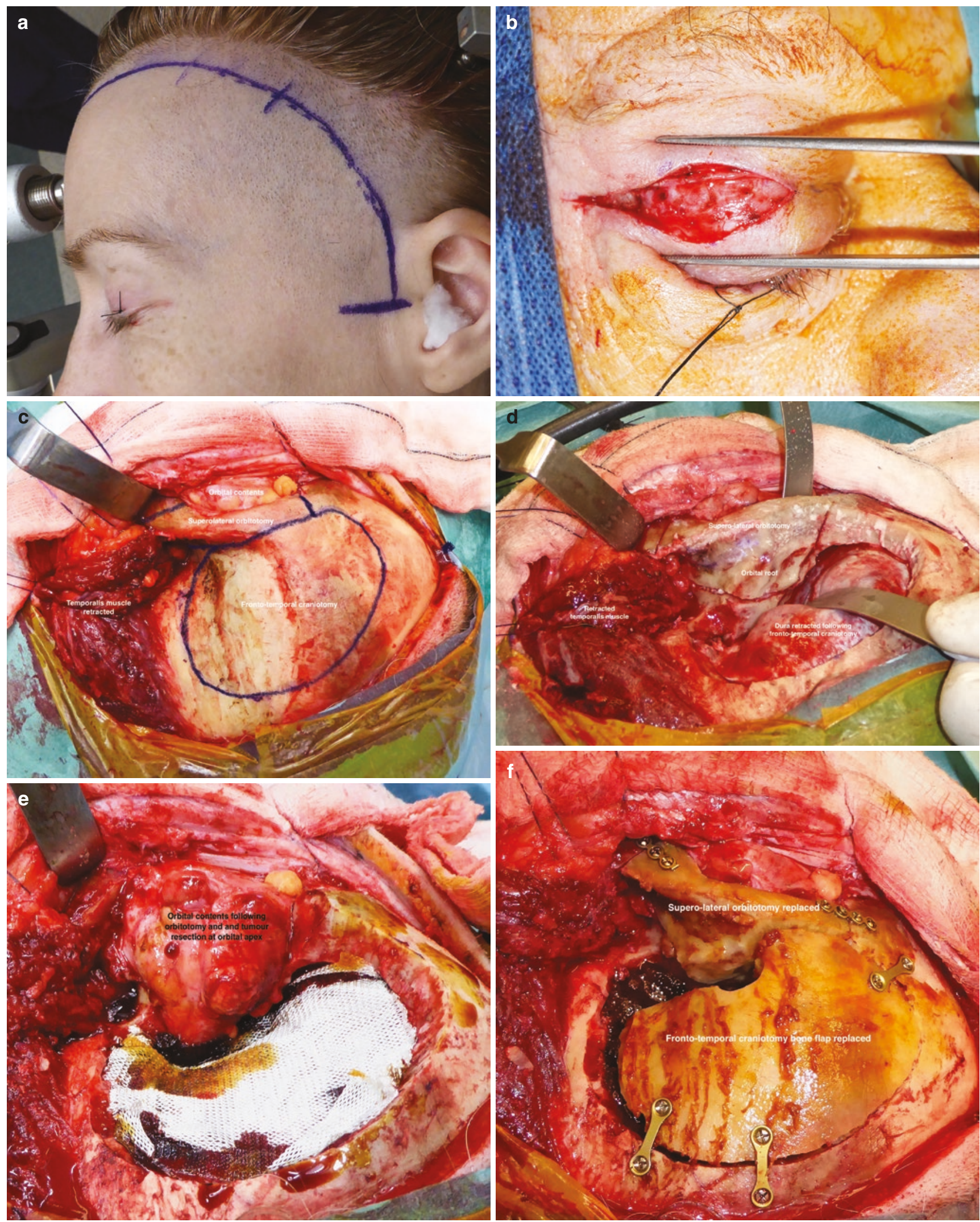

CAssociation of Oral and Maxillofacial Surgeons of India

Fig. 85.10 Lateral and superior orbitotomies. (a) Skin marking for a hemicoronal flap. (b) Upper eyelid skin crease incision for lateral orbitotomy. (c) Bone marking for superolateral orbitotomy and frontotem- poral craniotomy. (d) Superolateral orbitotomy bone cuts following craniotomy. (e) Exposure of the orbital contents following orbitotomy. (f) Craniotomy and orbitotomy bone flaps replaced 


\subsection{Conclusion}

Multiple routes are available to the clinician to access the pathology in the craniomaxillofacial region. The technical aspects of the individual procedures are described in detail, along with the potential alternatives and a progressive algorithm. An understanding of the relevant anatomy, a critical analysis of the extent of the lesion, exposure required and potential reconstruction helps in determining the most appropriate choice of procedure. There is no substitute to working within well-functioning teams to obtain the relevant clinical experience.

\subsection{Algorithms}

The following algorithms provide a potential sequence that can be considered for progressive access for pathologies in the head and neck region. The algorithms "exclude" endoscopic approaches that can be used in isolation or in combination with open access for lesions especially in the nose, orbit, anterior skull base and retromaxilla.

\section{Access to Buccal mucosa}

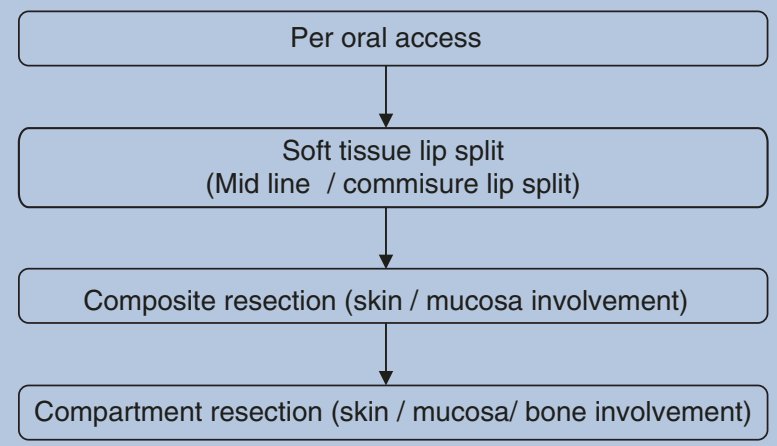

\section{Access to Tongue}

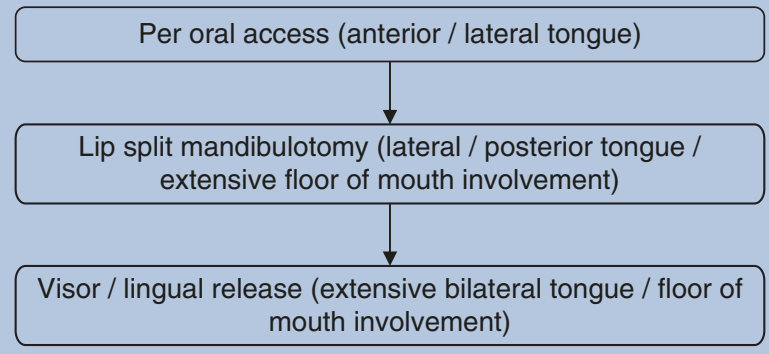

\section{Access to Mandible}

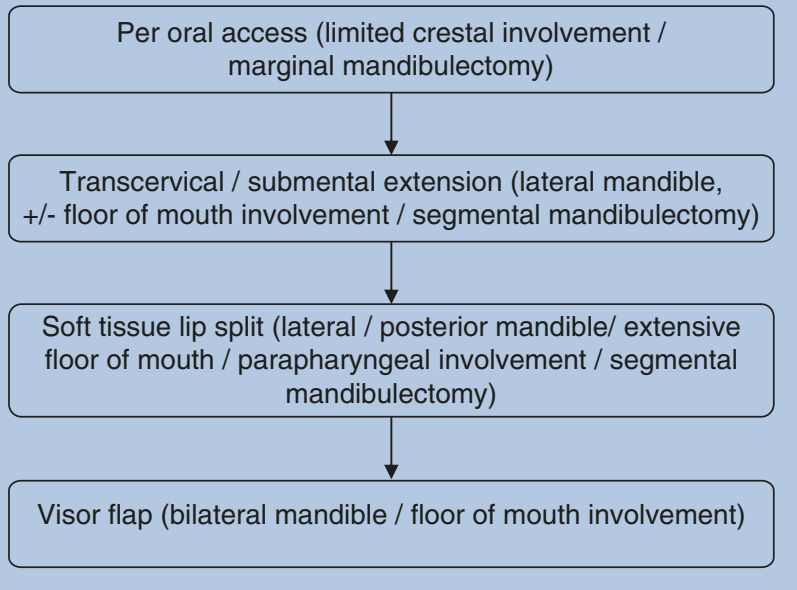

\section{Access to Maxilla*}

Per oral access (crestal / infra structure involvement)

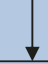

Modified Weber-Fergusson (More extensive maxillary involvement, but no significant orbital/ ethmoid or posterior extension)

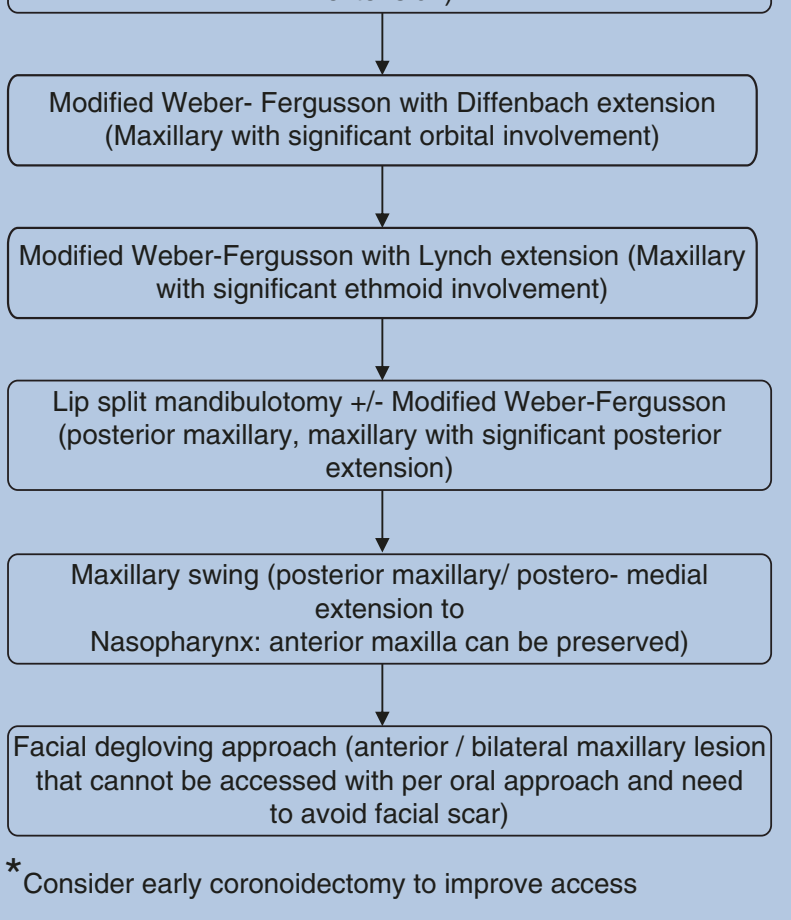




\section{Access to Nasal cavity*}

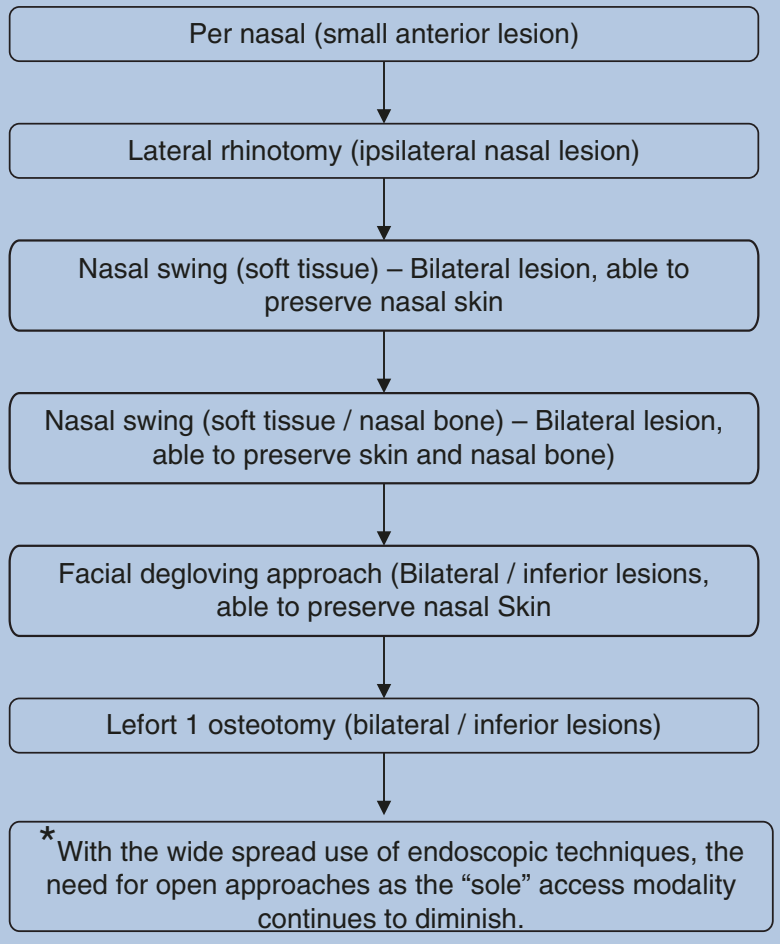

\section{Access to Orbitotomies}

(a) Lateral orbitotomy (lateral lesions / temporalis reconstruction)

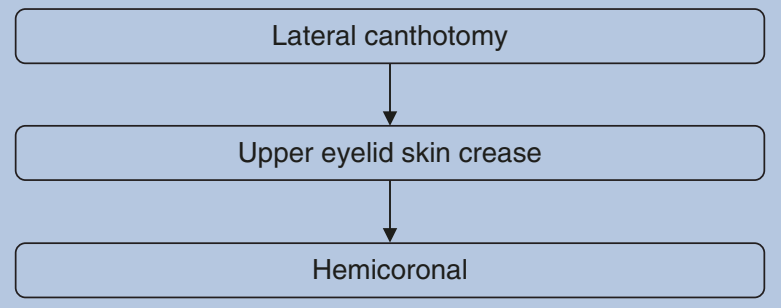

\section{(b) Lateral / superior orbitotomy (supero-lateral lesions / combined cranio- orbital lesions)}

Hemi coronal / Bicoronal flap with fronto-temporal craniotomy

(c) Inferior orbitotomy (inferior lesions)

Lower eyelid skin crease incision

\section{Access to Parapharyngeal space (deep lobe parotid / post styloid compartment pathology)}

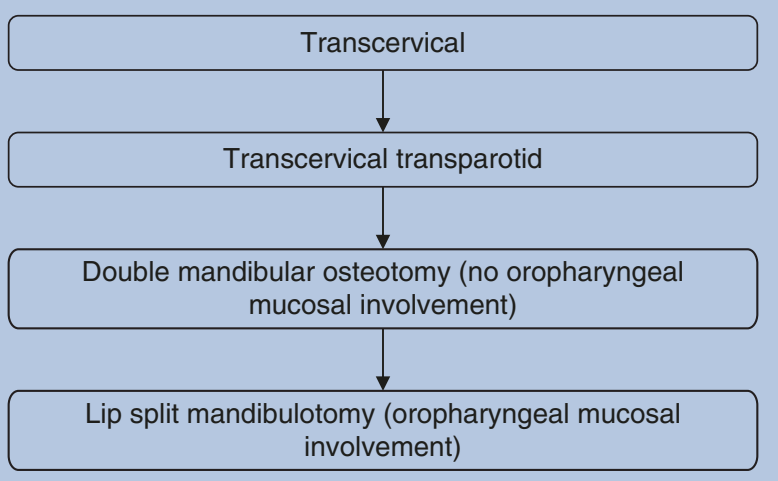

Common access procedures to the various sites ${ }^{\mathrm{a}}$

\begin{tabular}{|c|c|}
\hline Access & Procedure \\
\hline \multirow[t]{4}{*}{ Oral cavity } & Per oral \\
\hline & Soft tissue lip split \\
\hline & Lip split with access mandibulotomy \\
\hline & Visor flap \\
\hline \multirow[t]{6}{*}{ Maxilla } & Per oral \\
\hline & Modified Weber-Fergusson \\
\hline & $\begin{array}{l}\text { Modified Weber-Fergusson with Lynch and } \\
\text { eyelid extensions }\end{array}$ \\
\hline & Lip split mandibulotomy \\
\hline & Facial degloving \\
\hline & Combinations \\
\hline \multirow[t]{5}{*}{ Infratemporal fossa } & $\begin{array}{l}\text { Modified Weber-Fergusson with eyelid } \\
\text { extension and early coronoidectomy (with } \\
\text { maxillectomy) }\end{array}$ \\
\hline & Lip split mandibulotomy \\
\hline & Coronal flap with zygomatic osteotomy \\
\hline & Maxillary swing \\
\hline & Combinations \\
\hline \multirow[t]{5}{*}{ Nasal cavity } & Per nasal \\
\hline & Lateral rhinotomy \\
\hline & Nasal swing \\
\hline & Le fort 1 osteotomy \\
\hline & Facial degloving \\
\hline \multirow{3}{*}{$\begin{array}{l}\text { Pterygopalatine fossal } \\
\text { nasopharynx }\end{array}$} & Maxillary swing \\
\hline & Transpalatal approaches \\
\hline & Le fort 1 down fracture \pm midline split \\
\hline \multirow[t]{5}{*}{ Orbit } & Various soft tissue incisions \\
\hline & Lateral orbitotomy \\
\hline & Superior orbitotomy \\
\hline & Inferior orbitotomy \\
\hline & Combinations \\
\hline
\end{tabular}

${ }^{a}$ Excludes endoscopic approaches, which can be utilised alone or in combination with the open approaches 


\section{References}

1. Hartley F, Kenyon JH. Experiences in cerebral surgery. Ann Surg. 1907;45(4):481-530.

2. Tessier P. The definitive plastic surgical treatment of the severe facial deformities of craniofacial dysostosis: Crouzon's and Apertt's diseases. Plast Reconstr Surg. 1971;48(5):419-42.

3. Munro IR, Fearon JA. The coronal flap revisited. Plast Reconstr Surg. 1994;93(1):185-7.

4. Al-Kayat A, Bramley P. A modified pre-auricular approach to the temporomandibular joint and malar arch. Br J Oral Surg. 1979;17(2):91-103.

5. Kleinberger AJ, Jumaily J, Spiegel JH. Safety of modified coronal approach with dissection deep to temporalis fascia for facial nerve preservation. Otolaryngol Head Neck Surg. 2015;152(4):655-60.

6. Kadakia S, Badhey A, Ashai S, Lee TS, Ducic Y. Alopecia following bicoronal incisions. JAMA Facial Plast Surg. 2017;19(3):220-4.

7. Weber O. Vorstellung einer kranken mit resection des unterkiefers verhandlungen des naturhist. Med Vereins z Heidelberg. 1845;4:80-2. (in German)

8. Fergusson W. In operation of the upper jaw. A system of practical surgery. Edinburgh: John Churchill; 1842. p. 484.

9. Altemir FH. Transfacial access to the retromaxillary area. J Maxillofac Surg. 1986;14(3):165-70.

10. Dieffenbach JF. Die operative chirurgie. Leipzig: Brockans; 1845.

11. Lynch RC. The technique of a radical frontal sinus operation which has given me the best results. Laryngoscope. 1921;31:1.

12. Moure EJ. Traitment des tumors malignes primitives de l'ethmoide. Rev Laryngol Otol Rhinol (Bord). 1902; 23401-412.

13. Thankappan K, Sharan R, Iyer S, Kuriakose MA. Aesthetic and anatomic basis of modified lateral rhinotomy approach. J Oral Maxillofac Surg. 2009;67:231-4.

14. Conley J, Price JC. Sublabial approach to the nasal cavity and nasopharyngeal cavities. Am J Surg. 1979;38:615-8.

15. Maniglia AJ. Indications and techniques of midfacial degloving. Arch Otolaryngol Head Neck Surg. 1986;112(7):750-2.

16. Wei WL, Lam KH, Sham JT. New approach to the nasopharynx: the maxillary swing approach. Head Neck Surg. 1991;12:200-7.

17. Roux PJ, Butlin HT, Spencer GJ, editors. Diseases of the tongue. London: Cassell; 1900. p. 359.

18. Trotter W. Operations for malignant diseases of the pharynx. Br J Surgery. 1929;16:485.

19. McGregor IA, McDonald DG. Mandibular osteotomy in the surgical approach to the oral cavity. Head Neck Surg. 1983;5:457.

20. Hayter JP, Vaughan ED, Brown JS. Aesthetic lip splits. Br J Oral Maxillofac Surg. 1996;34:432.

21. Stanley RB. Mandibular lingual releasing approach to oral and oropharyngeal carcinomas. Laryngoscope. 1984;94:596-600.

22. Stringer SP, Randall Jordan J, Mendenhall WM, et al. Mandibular lingual releasing approach. Otolaryngol Head Neck Surg. 1992;107:395-8.

23. Spiro RH, Gerold FP, Strong EW. Mandibular swing approach for oral and oropharyngeal tumours. Head Neck Surg. 1981;3:371-8.

24. Attia EL, Bentley KC, Head T, Mulder D. A new external approach to the pterygomaxillary fossa and parapharyngeal space. Head Neck Surg. 1984;6(4):884-91.

25. Smith GI, Brennan PA, Webb AA, Ilankovan V. Vertical ramus osteotomy combined with a parasymphyseal mandibulotomy for improved access to the parapharyngeal space. Head Neck. 2003;25:1000-3.

26. Lesoin F, Pellerian P, Villette L, Autricque A, Jomin M. Value of the mobilisation of the orbito-zygomatico-malar flap. Neurochirurgie. 1986;32(1):90-3.
27. Hakuba A, Liu S, Nishimura S. The orbitozygomatic infratemporal approach: a new surgical technique. Surg Neurol. 1986;26:271-6.

28. Sindou M, Emery E, Acevedo G, Bem-David U. Respective indications for orbital rim, zygomatic arch and orbito-zygomatic osteotomies in the surgical approach to central skull base lesions. Critical, retrospective review in 146 cases. Acta Neurochir (Wein). 2001;143(10):967-75.

29. Kronlein RU. Zur Pathologie und operativen behandlung der dermoidcysten der orbita. Beitr Kilin Chir. 1888;4:149.

30. Berke RN. A modified Kronlein operation. Arch Ophthalmol. 1954;51:609.

31. Stallard HB. A plea for lateral orbitotomy with certain modifications. Brit J Ophthal. 1960;44:718-23.

32. Jane JA, Park TS, Pobereskin LH, Winn HR, Butler AB. The supraorbital approach: technical note. Neurosurgery. 1982;11(4):537-42.

33. Al-Mefty O. Supra-orbital -pterional approach to skull base lesions. Neurosurgery. 1987;21:474-7.

\section{Additional Readings}

Ethunandan M, Evans BT, Lang D. Access surgery. In: Langdon J, Patel M, Ord R, Brennan P, editors. Operative oral \& maxillofacial surgery. 3rd ed. London: Hodder Arnold; 2017.

Ethunandan M. Infra-temporal fossa and pterygopalatine fossa. In: Brenna PA, Standring S, Wiseman SM, editors. Gray's surgical anatomy. St. Louis, MO: Elsevier; 2019.

Chatni SC, Sharan R, Patel D, Iyer S, Tiwari RM, Kuriakose MA. Transmandibular approach for excision of maxillary sinus tumors extending to the pterygopalatine and infratemporal fossa. Oral Oncol. 2009;45:720-6.

Shahinian H, Dornier MD, Fisch U. Parapharyngeal space tumours: the infratemporal fossa approach. Skull Base Surg. 1995;5:73-81.

Evans BT, Wiesenfeld D, Clauser L, Curioni C. Surgical approaches to the infratemporal fossa. In: Langdon J, BKB B, Moxham BJ, editors. Surgical anatomy of the infratemporal fossa. London: Martin Dunitz; 2003.

\section{Lateral Rhinotomy}

Mertz JS, Pearson BW, Kern EB. Lateral rhinotomy. Indications, technique, and a review of 226 patients. Arch Otolaryngol. 1983;109(4):235-9.

\section{Lip Split}

Rapidis AD, Valsamis S, Anterriotis DA, Skouteris CA. Functional and aesthetic results of various lip splitting incisions: a clinical analysis of 60 cases. J Oral Maxillofac Surg. 2001;59:1292-6.

\section{Double Mandibular Osteotomies}

Kolokythas A, Eisle DW, El-Sayed I, Schmidt BL. Mandibular osteotomies for access to select parapharyngeal space neoplasms. Head Neck. 2009;31(1):102-10.

Flood TR, Hislop WS. A modified surgical approach for parapharyngeal space tumours: use of the inverted "L" osteotomy. Br J Oral Maxillofacial Surg. 1991;29(2):82-6.

Schlieve T, Carlson ER, Freeman M, Buckley R, Arnold J. The double mandibular osteotomy for vascular and tumour surgery of the parapharyngeal space. J Oral Maxillofac Surg. 2017;75:1046-61. 
Open Access This chapter is licensed under the terms of the Creative Commons Attribution 4.0 International License (http://creativecommons. org/licenses/by/4.0/), which permits use, sharing, adaptation, distribution and reproduction in any medium or format, as long as you give appropriate credit to the original author(s) and the source, provide a link to the Creative Commons license and indicate if changes were made.

The images or other third party material in this chapter are included in the chapter's Creative Commons license, unless indicated otherwise in a credit line to the material. If material is not included in the chapter's Creative Commons license and your intended use is not permitted by statutory regulation or exceeds the permitted use, you will need to obtain permission directly from the copyright holder.

(c) (1) 